Article

\title{
Development of a Potential Gallium-68-Labelled Radiotracer Based on DOTA-Curcumin for Colon-Rectal Carcinoma: From Synthesis to In Vivo Studies
}

\author{
Giulia Orteca ${ }^{1}$, Federica Pisaneschi ${ }^{2}$ DD, Sara Rubagotti ${ }^{3}$, Tracy W. Liu ${ }^{2}$, Giacomo Biagiotti ${ }^{2,4}$, \\ David Piwnica-Worms ${ }^{2}$, Michele Iori ${ }^{3}$, Pier Cesare Capponi ${ }^{3}$, Erika Ferrari ${ }^{1, * \mathbb{D}}$ and \\ Mattia Asti ${ }^{3}$
}

1 Department of Chemical and Geological Sciences, University of Modena and Reggio Emilia, via G. Campi 103, 41125 Modena, Italy; giulia.orteca@unimore.it

2 Department of Cancer Systems Imaging, The University of Texas MD Anderson Cancer Center, 1881 East Road, Houston, TX 77054, USA; FPisaneschi@mdanderson.org (F.P.); twliu@mdanderson.org (T.W.L.); biagio2588@gmail.com (G.B.); dpiwnica-worms@mdanderson.org (D.P.-W.)

3 Radiopharmaceutical Chemistry Unit, Oncologic and High Technologies Department, Azienda USL-IRCCS, via Amendola 2, 42122 Reggio Emilia, Italy; sara.rubagotti@libero.it (S.R.); michele.iori@ausl.re.it (M.I.); piercesare.capponi@ausl.re.it (P.C.C.); mattia.asti@ausl.re.it (M.A.)

4 Department of Chemistry “Ugo Schiff”, Università di Firenze, via della Lastruccia 3-13, 50019 Sesto Fiorentino, Italy

* Correspondence: erika.ferrari@unimore.it; Tel.: + 39-059-2058631; Fax: + 39-059-205-8631

Academic Editor: Anne Roivainen

Received: 2 January 2019; Accepted: 6 February 2019; Published: 12 February 2019

\begin{abstract}
Colorectal cancer is the third most commonly occurring cancer in men and the second most commonly occurring cancer in women worldwide. We have recently reported that curcuminoid complexes labelled with gallium-68 have demonstrated preferential uptake in HT29 colorectal cancer and K562 lymphoma cell lines compared to normal human lymphocytes. In the present study, we report a new gallium-68-labelled curcumin derivative $\left({ }^{68} \mathrm{Ga}-\mathrm{DOTA}-\mathrm{C} 21\right)$ and its initial validation as marker for early detection of colorectal cancer. The precursor and non-radioactive complexes were synthesized and deeply characterized by analytical methods then the curcuminoid was radiolabelled with gallium-68. The in vitro stability, cell uptake, internalization and efflux properties of the probe were studied in HT29 cells, and the in vivo targeting ability and biodistribution were investigated in mice bearing HT29 subcutaneous tumour model. ${ }^{68}$ Ga-DOTA-C21 exhibits decent stability $(57 \pm 3 \%$ after 120 min of incubation) in physiological media and a curcumin-mediated cellular accumulation in colorectal cancer cell line (121 $\pm 4 \mathrm{KBq}$ of radiotracer per $\mathrm{mg}$ of protein within $60 \mathrm{~min}$ of incubation). In HT29 tumour-bearing mice, the tumour uptake of ${ }^{68} \mathrm{Ga}$-DOTA-C21 is $3.57 \pm 0.3 \%$ of the injected dose per gram of tissue after $90 \mathrm{~min}$ post injection with a tumour to muscle ratio of $2.2 \pm 0.2$. High amount of activity $(12.73 \pm 1.9 \% \mathrm{ID} / \mathrm{g})$ is recorded in blood and significant uptake of the radiotracer occurs in the intestine $(13.56 \pm 3.3 \% \mathrm{ID} / \mathrm{g})$, lungs $(8.42 \pm 0.8 \% \mathrm{ID} / \mathrm{g})$, liver $(5.81 \pm 0.5 \% \mathrm{ID} / \mathrm{g})$ and heart $(4.70 \pm 0.4 \% \mathrm{ID} / \mathrm{g})$. Further studies are needed to understand the mechanism of accumulation and clearance; however, ${ }^{68} \mathrm{Ga}$-DOTA-C21 provides a productive base-structure to develop further radiotracers for imaging of colorectal cancer.
\end{abstract}

Keywords: gallium-68; radiotracers; positron emission tomography; curcuminoids; colorectal cancer 


\section{Introduction}

Colorectal cancer (CRC) is the third most commonly occurring cancer in men and the second in women worldwide, with more than 1.4 million new cancer cases every year [1]. India has a relatively low prevalence of CRC in comparison to other countries, mainly attributed to differences in dietary patterns and lifestyles [2]. It is widely known that curcumin (1,7-bis(4-hydroxy-3-methoxyphenyl)-1,6-heptadiene-3,5-dione), a phyto-polyphenol pigment isolated from the dried rhizomes of Curcuma longa L., has been used for centuries in Asian countries as a dietary spice and traditional drug to treat many different diseases [3]. Besides having antioxidant, anti-inflammatory, anti-bacterial and anti-amyloid properties, curcumin has been shown also to possess anti-cancer activities [4,5]. In particular, the ability to inhibit proliferation of a wide variety of tumour types, including colorectal cancer, has been highlighted by recent studies in vitro and in vivo [6-8]. Several studies suggest that curcumin changes the gene expression profiles and signalling pathways such as those involving COX-2 enzymes as well as NF-kB, cyclin D1 and p53 proteins [9-11]. Although the mechanism of curcumin's high accumulation and cytotoxic activity against HeLa, MCF-7, HT29, and HCT-116 cancer cell lines are still unclear [10,11], curcumin itself is a promising tumour-targeting moiety for the development of early diagnosis and therapeutic agents. Nuclear medicine imaging provides information about biological processes occurring at a molecular level in vivo; this occurs by following the fate of radiolabelled compounds. Such radiotracers can be substrates for metabolic pathways overexploited in tumour cells or have particular affinity for receptors overexpressed in tumours. Hence, curcumin derivatives labelled with proper $\beta^{+}$emitter radionuclides or curcumin-based radio-metal complexes have the potential to be diagnostic tools for positron emission tomography (PET). Currently, radiolabelled curcuminoids have been mostly investigated for imaging of the central nervous system (CNS) where several curcumin-based probes labelled with fluorine-18 have demonstrated promise in the early detection of Alzheimer's disease [12,13]. In oncology, curcuminoids as imaging agents are underinvestigated. We have recently reported that curcuminoid complexes labelled with gallium-68 demonstrated preferential uptake in HT29 colorectal cancer and K562 lymphoma cell lines compare to normal human lymphocytes. In that study, the core radio-metal was directly linked to two curcuminoid molecules through the keto-enol moiety [14,15]. The curcuminoid complexes showed good stability in PBS and human serum but were rapidly degraded in whole human blood. These findings, in addition to the low stability and solubility of curcumin structures in physiological media [16], limited the possibility to further study these kind of compounds in vivo. In the present study, we report a new gallium-68-labelled curcumin derivative with curcumin linked to an efficient gallium-68 chelator, 1,4,7,10-tetraazacyclododecane-1,4,7,10-tetraacetic acid (DOTA), and its initial validation as a marker for early detection of CRC. The synthetic pathway, chemical characterization, labelling methods, stability, cell uptake, internalization and efflux studies on HT29 cells and in vivo micro-PET imaging and biodistribution in colorectal tumour bearing mice of this radiotracer are herein reported.

\section{Results}

\subsection{Synthesis and Chemical Characterization}

Synthesis of 1,4,7,10-tetraazacyclododecane-1,4,7,10-tetraacetic(1,7-bis(4-hydroxy-3-methoxyphenyl) -1,6-heptadiene-3,5-dione (DOTA-C21) was carried out in two steps as shown in Figure 1. The curcumin-based conjugate was identified and completely characterized by ESI-LC/MS (Figure S1) and ${ }^{1} \mathrm{H}-,{ }^{13} \mathrm{C}-\mathrm{NMR}$ spectroscopy (Figures S2, S3). ESI-LC/MS spectrum exhibits two isomeric peaks $(\mathrm{m} / \mathrm{z}=$ 798.3; $[\mathrm{M}+\mathrm{H}]^{+}$) that were attributed to contemporary presence of two main isomeric forms (diketo and keto-enol) as previously reported for curcumin and its derivatives $[17,18]$. Gallium complexes were obtained by reacting a DOTA-C21 solution with a $\mathrm{Ga}\left(\mathrm{NO}_{3}\right)_{3}$ solution at $95{ }^{\circ} \mathrm{C}$ for 30 min in a $1.5: 1$ metal to ligand molar ratio using a $0.4 \mathrm{M}$ ammonium acetate solution as buffer. Complexes formation was identified by ESI-LC/MS analysis thanks to the typical isotopic pattern of gallium ion (Figures S4, S5). 
Similar to the free ligand analysis, the spectrum exhibits two compounds with the same $m / z$ (retention times: 2.8 and $3.3 \mathrm{~min}$, respectively) both corresponding to Ga-DOTA-C21 complexes $\left(\mathrm{m} / z=864.2\left[\mathrm{M}^{69} \mathrm{Ga}\right.\right.$ $\left.+\mathrm{H}]^{+}-866.2\left[\mathrm{M}^{71} \mathrm{Ga}+\mathrm{H}\right]^{+}\right)$. To elucidate chelation mode and binding sites, ${ }^{1} \mathrm{H}-\mathrm{NMR}$ titration of DOTA-C21 with $\mathrm{Ga}^{3+}$ was also performed (Figure S6) and the gallium(III)-complex was characterized by NMR (Figure 2, Figure S7) as well as LC-MS/MS fragmentation experiments (Figure 3, Figure S8).
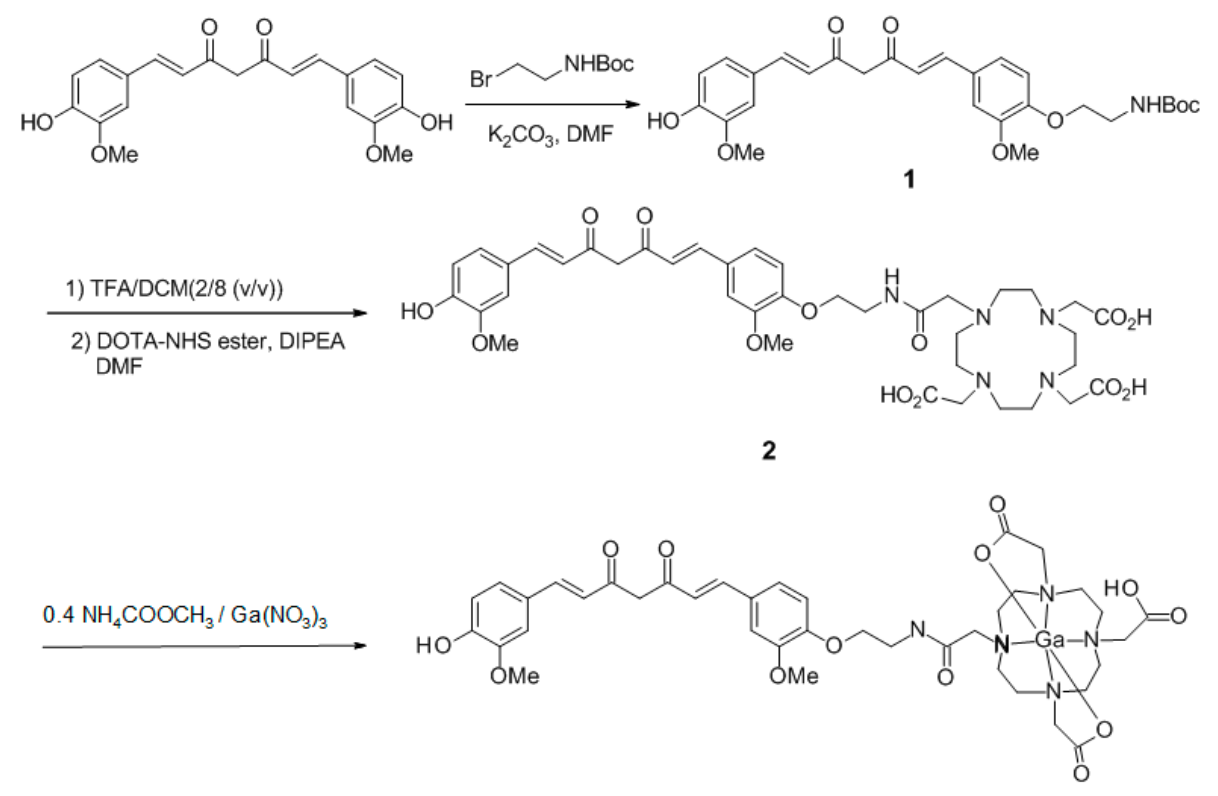

Figure 1. Synthetic pathway for the preparation of DOTA-C21 and its complexation with Ga(III) by reacting DOTA-C21 with $\mathrm{Ga}\left(\mathrm{NO}_{3}\right)_{3}$ at 1.5:1 metal-to-ligand molar ratio in 0.4 M ammonium acetate solution for $30 \mathrm{~min}$ at $95^{\circ} \mathrm{C}$.

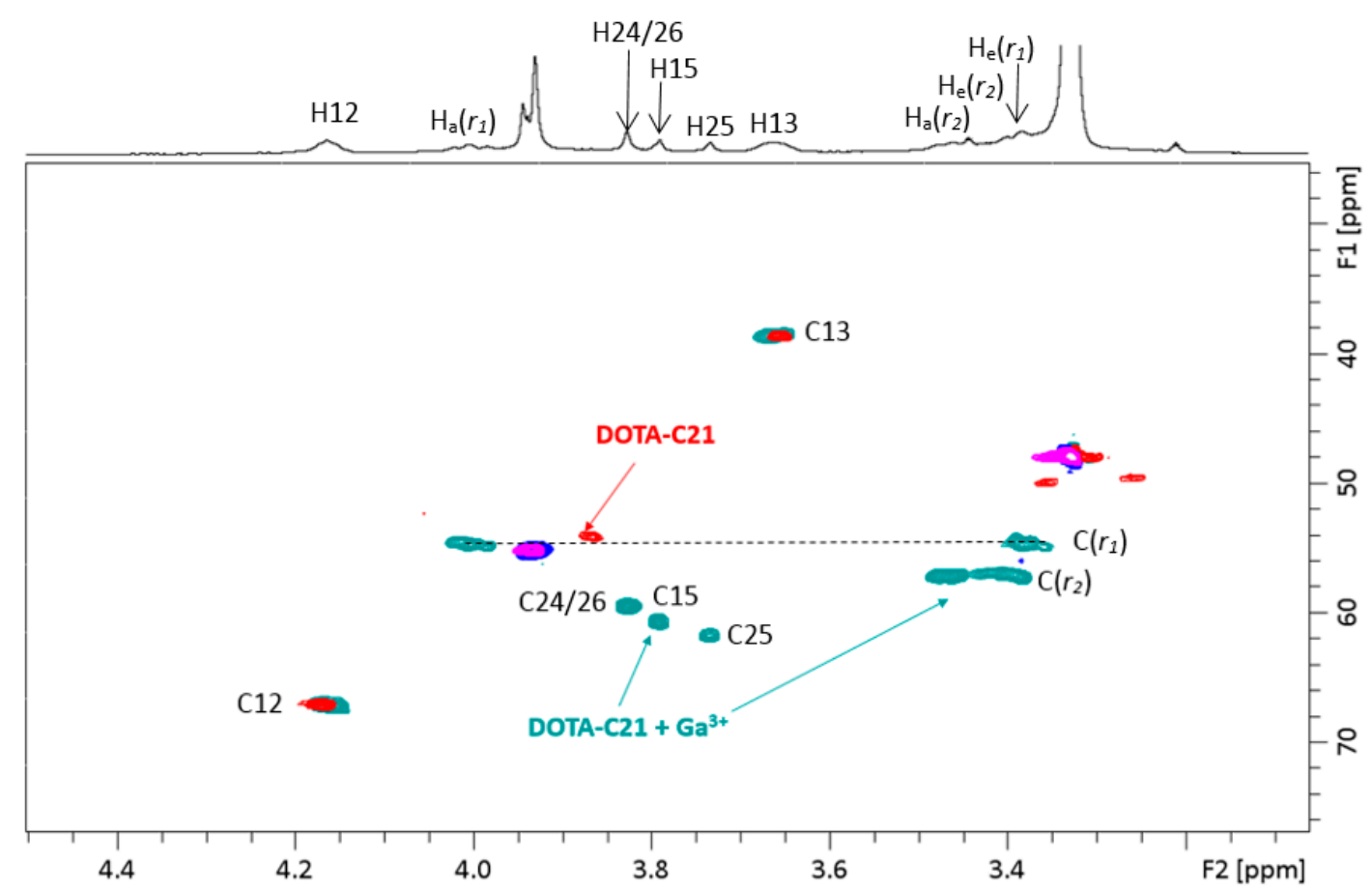

Figure 2. Aliphatic region overlap of ${ }^{1} \mathrm{H}-,{ }^{13} \mathrm{C}-\mathrm{HSQC}-\mathrm{NMR}$ spectra of DOTA-C21 (red $\left(\mathrm{CH}_{2}\right)$ and purple $\left.\left(\mathrm{CH} / \mathrm{CH}_{3}\right)\right)$ and Ga-DOTA-C21 (green $\left(\mathrm{CH}_{2}\right)$ and blue $\left(\mathrm{CH} / \mathrm{CH}_{3}\right)$ ). All the spectra were acquired in MeOD- $d_{4}$ at $25^{\circ} \mathrm{C}([$ DOTA-C21] $=0.63 \mathrm{mM})$. Atom numbering refers to Figures 11 and 12 . 

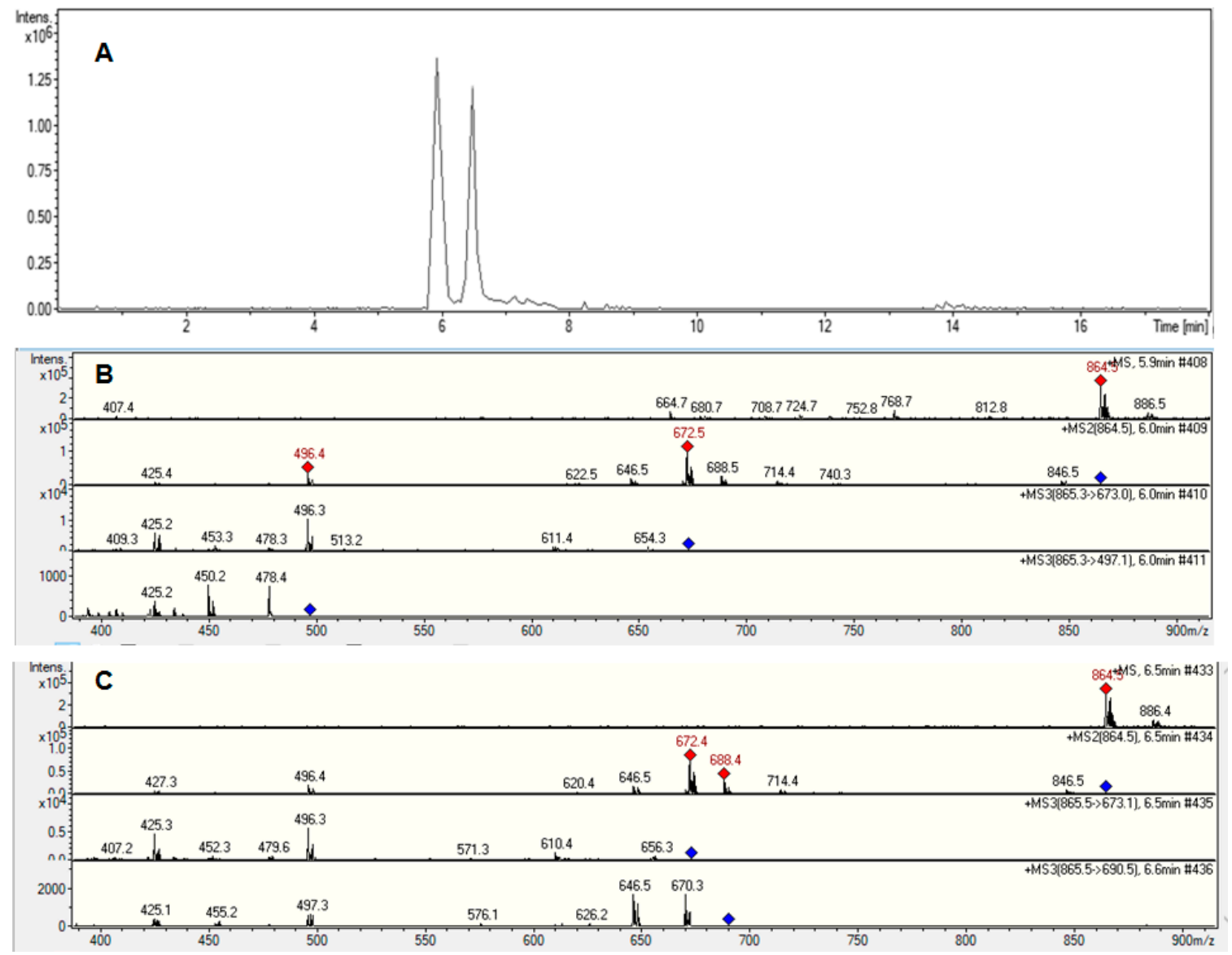

Figure 3. LC-MS/MS fragmentation experiments on Ga-DOTA-C21 complexes with $m / z 864.5[\mathrm{M}+\mathrm{H}]^{+}$. HPLC-MS chromatogram (A). Fragmentation pathway of the $m / z 864.5[\mathrm{M}+\mathrm{H}]^{+}$ion corresponding to the peak with retention time $5.9 \mathrm{~min}(\mathbf{B})$. Fragmentation pathway of the $m / z 864.5[\mathrm{M}+\mathrm{H}]^{+}$ion corresponding to the peak with retention time $6.5 \mathrm{~min}(\mathbf{C})$.

${ }^{1} \mathrm{H}$ - and ${ }^{13} \mathrm{C}-\mathrm{NMR}$ spectra displayed a strong shift of both protons and carbon with respect to the free ligand when gallium(III) is added. In particular, methylene protons of the chelator ring, briefly $r_{1}$ and $r_{2}$, are no longer chemical shift equivalent since the interconversion between pseudo-axial $\left(\mathrm{H}_{\mathrm{a}}\right)$ and pseudo-equatorial $\left(\mathrm{H}_{\mathrm{e}}\right)$ conformation is prevented by metal complexation. Geminal protons $\mathrm{H}_{\mathrm{a}}\left(r_{1}\right)$ and $\mathrm{H}_{\mathrm{e}}\left(r_{1}\right)$ appear as broad triplets at $4.00 \mathrm{ppm}$ and 3.38, respectively, due to similar values of geminal $\left({ }^{2} \mathrm{~J}_{\mathrm{HH}}\right)$ and vicinal $\left({ }^{3} \mathrm{~J}_{\mathrm{HH}}\right)$ coupling constants $(\sim 14 \mathrm{~Hz})$. The same situation occurs for $\mathrm{H}_{\mathrm{a}}\left(r_{2}\right)$ and $\mathrm{H}_{\mathrm{e}}\left(r_{2}\right)$ that fall at $3.47 \mathrm{ppm}$ and $3.41 \mathrm{ppm}$, respectively. Assignments of ring protons was confirmed by ${ }^{1} \mathrm{H}^{13} \mathrm{C}$-HSQC spectrum, $\mathrm{H}_{\mathrm{a}} / \mathrm{H}_{\mathrm{e}}\left(r_{1}\right)$ show cross-peaks with carbon at $54.65 \mathrm{ppm}\left(\mathrm{C}\left(r_{1}\right)\right)$ and $\mathrm{H}_{\mathrm{a}} / \mathrm{H}_{\mathrm{e}}\left(r_{2}\right)$ with a carbon at $57.11 \mathrm{ppm}\left(\mathrm{C}\left(r_{2}\right)\right)$. The methylene groups of acetate arms are not chemical shift equivalent in gallium complex and appear as broad singlets in proton spectrum. The following reasonable assignments can be proposed (for atom numbering refers to Sections 4.1.1 and 4.1.2): $\mathrm{CH}_{2}$ in $\alpha$ to amide and nitrogen (atom numbering 15) ${ }^{1} \mathrm{H}-3.79 \mathrm{ppm}$ and ${ }^{13} \mathrm{C}-60.64 \mathrm{ppm} ; \mathrm{CH}_{2}$ in $\alpha$ to carboxylic group involved in gallium coordination (atom numbering 24 and 26) ${ }^{1} \mathrm{H}-3.83 \mathrm{ppm}$ and ${ }^{13} \mathrm{C}$ $59.41 \mathrm{ppm} ; \mathrm{CH}_{2}$ in $\alpha$ to free carboxylic group (atom numbering 25 ) ${ }^{1} \mathrm{H}-3.74 \mathrm{ppm},{ }^{13} \mathrm{C}-61.68 \mathrm{ppm}$.

Moreover, UV absorption and fluorescent emission spectra upon increasing addition of $\mathrm{Ga}^{3+}$ from free ligand were acquired (Figures S9, S10). These analyses showed that DOTA-C21 displays an absorption maximum at $410 \mathrm{~nm}$, typical of curcumin structure in the keto-enol form. Upon addition of gallium (III) solution, an increase in absorbance is observed at $290 \mathrm{~nm}$, while no changes are observed for the absorption maximum. Fluorescence emission spectra of DOTA-C21 ( $\left.\lambda_{\mathrm{ex}} 410 \mathrm{~nm}\right)$ do not show any significant change after gallium(III) addition. 


\subsection{Radiolabelling of the Chelator-Curcuminoid Derivatives with Gallium-68}

Radiolabelling was performed using two methods. In the first, postprocessing of the generator elution was performed by cation exchange purification [19] and kinetics of the labelling were studied between 1 and $20 \mathrm{~min}$ by TLC. Kinetics were fast and the incorporation yield was $97 \pm 2 \%$ after 5 min at $95{ }^{\circ} \mathrm{C}(n=3)$. Postprocessing of the generator elution minimizes the metal cation impurities allowing a complete radiolabelling of DOTA-C21 by using only $10 \mathrm{nmol}$ of the precursor. Representative TLC analyses are shown in Figure S11. In the second method, labelling without processing of the elution was attempted with increasing amount of precursor (20, 40, 60, $80 \mathrm{nmol})$. In this case, a reproducible radiolabelling could only be achieved with $80 \mathrm{nmol}$ of DOTA-C21 after $10 \mathrm{~min}$ at $95{ }^{\circ} \mathrm{C}$, with an incorporation yield ranging from 60 to $80 \%$. The crude mixture was further purified by SPE to eliminate unreacted gallium-68 and hydrolysed products. Radiochemical purity was assessed by UHPLC $(\mathrm{RCP}>95 \%, \mathrm{RCY}=55 \pm 5 \%, n=10)$. Representative UHPLC chromatograms (radiochemical detector) of a ${ }^{68} \mathrm{Ga}$-DOTA-C21 preparation before and after SPE purification are shown in Figure 4. Similarly, to the complexation reaction with natural gallium, two main radioactive species were obtained with a retention time of 4.7 and $5.1 \mathrm{~min}$, respectively. Based on the data gathered for the non-radioactive preparation, the peaks were assigned to two ${ }^{68} \mathrm{Ga}-\mathrm{DOTA}-\mathrm{C} 21$ isomeric complexes. A further peak at 5.3 min was recorded (ca. $4 \%$ of total radioactivity) and was likely due to a gallium-68 complexes with a degraded form of the precursor at labelling conditions. In both methods, the pH was kept constant around 4.

\subsection{In Vitro Stability Studies}

In vitro stability of ${ }^{68} \mathrm{Ga}-\mathrm{DOTA}-\mathrm{C} 21$ complexes in PBS, human serum (HS) and whole human blood (HB) were determined according to peak integration of analytical UHPLC (Figure 5). Stability of ${ }^{68} \mathrm{Ga}-D O T A-C 21$ in PBS was more than $88 \pm 3 \%$ after $120 \mathrm{~min}$ at $37{ }^{\circ} \mathrm{C}$. In HS, the radiotracer was also stable with $85 \pm 3 \%$ of intact compound after $120 \mathrm{~min}$ of incubation. On the contrary, in whole blood, ${ }^{68} \mathrm{Ga}-D O T A-C 21$ was partially degraded to more polar metabolites already after $10 \mathrm{~min}$ of incubation. The amount of intact compound ranged from $74 \pm 2 \%$ after 10 min to $57 \pm 3 \%$ after 120 min of incubation.

\subsection{Uptake, Internalization and Efflux in Colorectal Cancer Cell Line}

In vitro ${ }^{68} \mathrm{Ga}$-DOTA-C21 uptake studies demonstrated time-dependent cellular accumulation in HT29 colorectal cancer cell line. Total uptake increased continuously in the first 60 min of incubation up to $121 \pm 4 \mathrm{KBq}$ of radiotracer per $\mathrm{mg}$ of protein $(n=3)$. At 60 min post incubation, $83 \%$ of total radioactivity was internalized in the cells. Conversely, ${ }^{68} \mathrm{GaCl}_{3}$, used as a negative control, demonstrated significantly lower in vitro cell uptake $(20 \pm 4 \mathrm{KBq} / \mathrm{mg}$ of protein after $60 \mathrm{~min}$ of incubation, $n=3$ ) confirming the curcuminoid-mediated uptake by HT29 cells (Figure 6A,B). The cellular uptake of ${ }^{68} \mathrm{Ga}-\mathrm{DOTA}-\mathrm{C} 21$ is comparable to that of the compound obtained by direct labelling of curcumin with gallium-68 (i.e., ${ }^{68} \mathrm{Ga}(\mathrm{CUR})_{2}$ complexes [15]), however the internalized fraction was more than doubled. To test for receptor-mediated uptake, HT29 cells were preincubated with a 200 -fold excess of calcitriol, the natural ligand for vitamin D receptor (VDR), and then ${ }^{68}$ Ga-DOTA-C21 was added. The experiments were performed to assess whether ${ }^{68} \mathrm{Ga}-\mathrm{DOTA}-\mathrm{C} 21$ uptake was mediated by VDR since it has been reported that curcumin has a structure suitable to bind nuclear vitamin $\mathrm{D}$ receptor. The difference between uptake with or without calcitriol was not statistically significant $(n=3$, Figure 6C) suggesting that the VDR receptor was not involved in the uptake or that the receptor cannot be saturated in these conditions. 

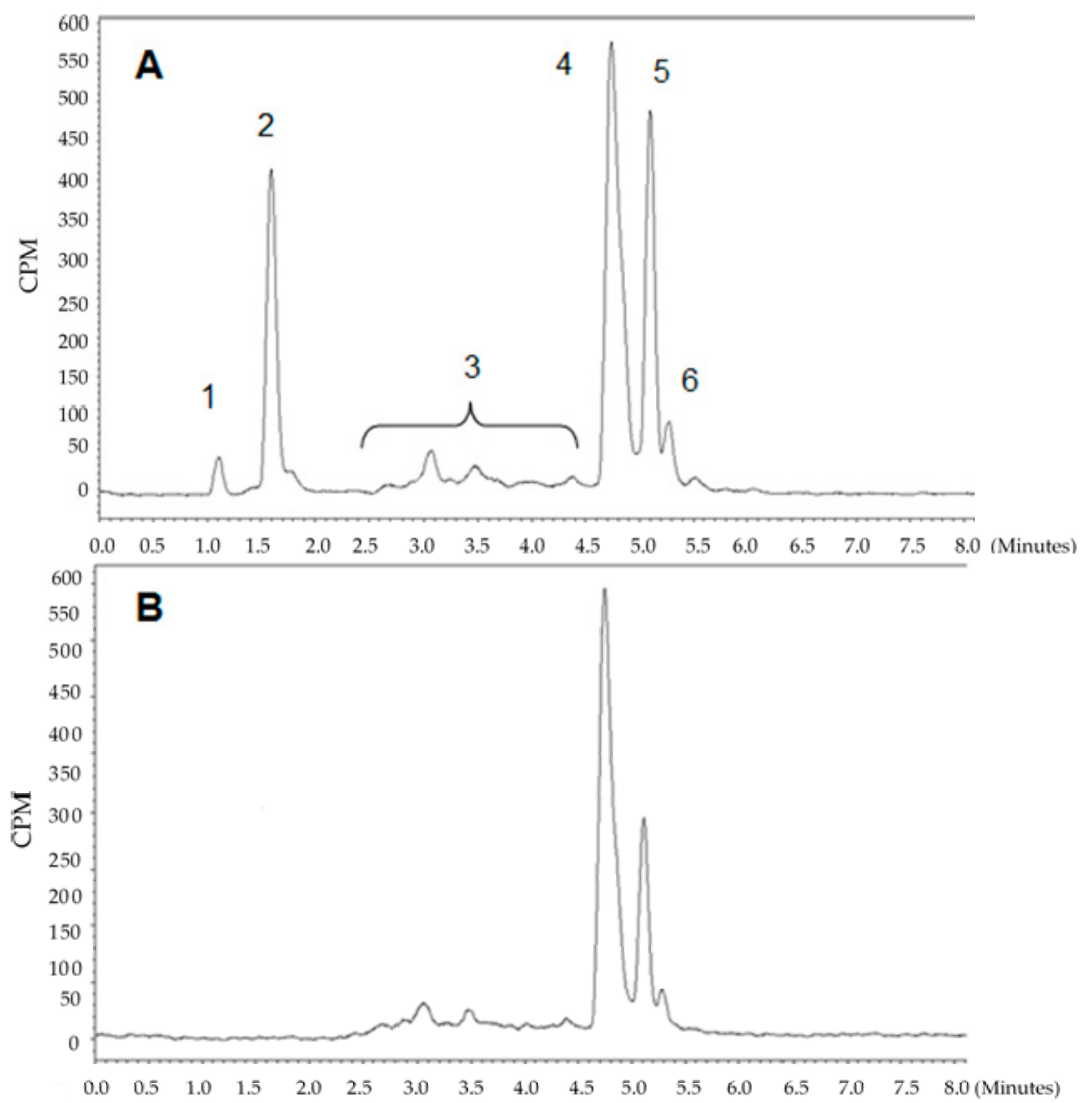

Figure 4. Representative UHPLC chromatograms (radiochemical detector) of a ${ }^{68}$ Ga-DOTA-C21 preparation before (A) and after (B) SPE purification. (1) ${ }^{68} \mathrm{Ga}-$ free, (2) ${ }^{68} \mathrm{Ga}$-hydrolyzed products, (3) ${ }^{68} \mathrm{Ga}$-labelled byproducts, (4) and (5) ${ }^{68} \mathrm{Ga}$-DOTA-C21 isomers, (6) ${ }^{68} \mathrm{Ga}$-labelled degradation product.

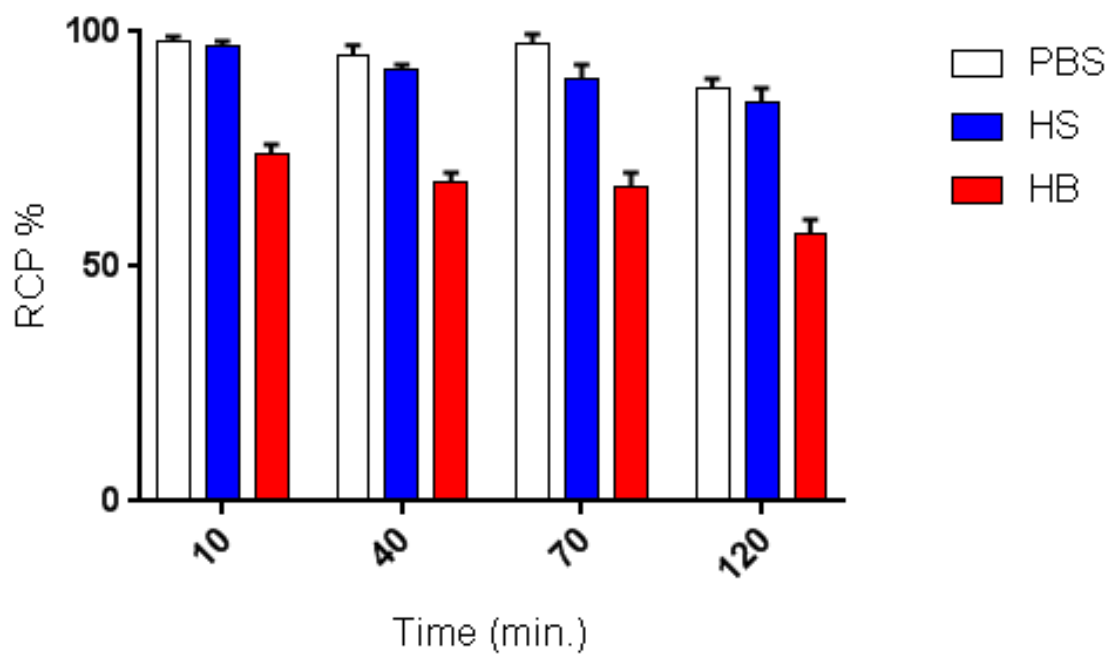

Figure 5. Stability of ${ }^{68}$ Ga-DOTA-C21 complex incubated over time (10, 40, 70, $120 \mathrm{~min}$.) in different media $(n=3$, mean $\pm \mathrm{SD})$. 

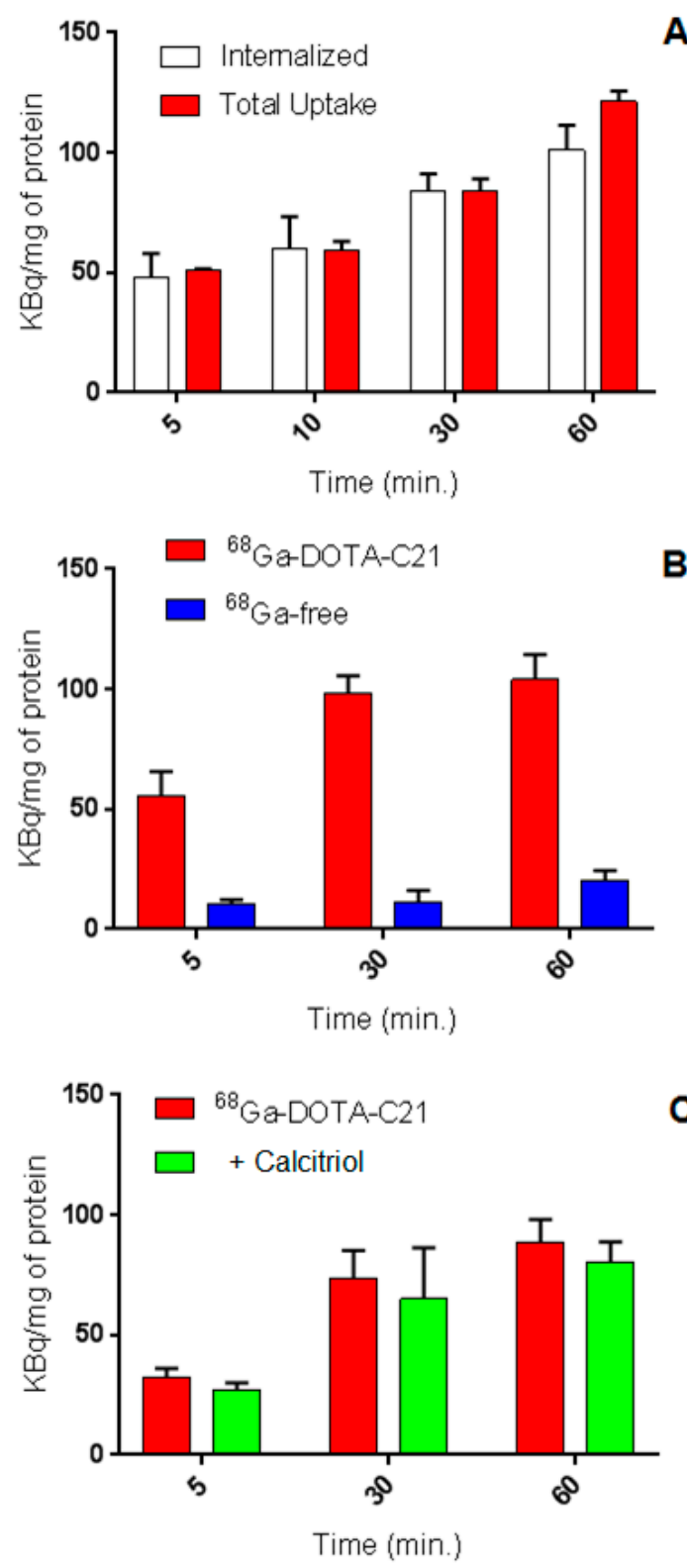

Figure 6. Uptake and internalization at different time points of ${ }^{68} \mathrm{Ga}-\mathrm{DOTA}-\mathrm{C} 21$ in HT-29 colorectal cancer cell line ( $n=3$, mean $\pm \mathrm{SD}$ ) (A). Comparison between the uptake of ${ }^{68} \mathrm{Ga}$-DOTA-C21 and ${ }^{68} \mathrm{GaCl}_{3}$ in HT-29 cells indicating curcumin structure dependent accumulation $(n=3$, mean $\pm \mathrm{SD})$ (B). Comparison between the uptake of ${ }^{68} \mathrm{Ga}$-DOTA-C21 and ${ }^{68} \mathrm{Ga}-\mathrm{DOTA}-\mathrm{C} 21+$ calcitriol in HT-29 cells $(n=3$, mean $\pm \mathrm{SD})(\mathrm{C})$.

For efflux studies, cells were incubated with ${ }^{68} \mathrm{Ga}$-DOTA-C21 and the uptake was stopped after $60 \mathrm{~min}$ by removing the supernatant. Then, cells were washed, fresh medium was added and they were incubated again for different periods of time. Media were collected and radioactivity released from the cells was measured $.^{68} \mathrm{Ga}-\mathrm{DOTA}-\mathrm{C} 21$ showed a slow externalization pattern with around $75 \%$ $(n=3)$ of the radiotracer remaining within the cell after $60 \mathrm{~min}$ of incubation (Figure 7). 


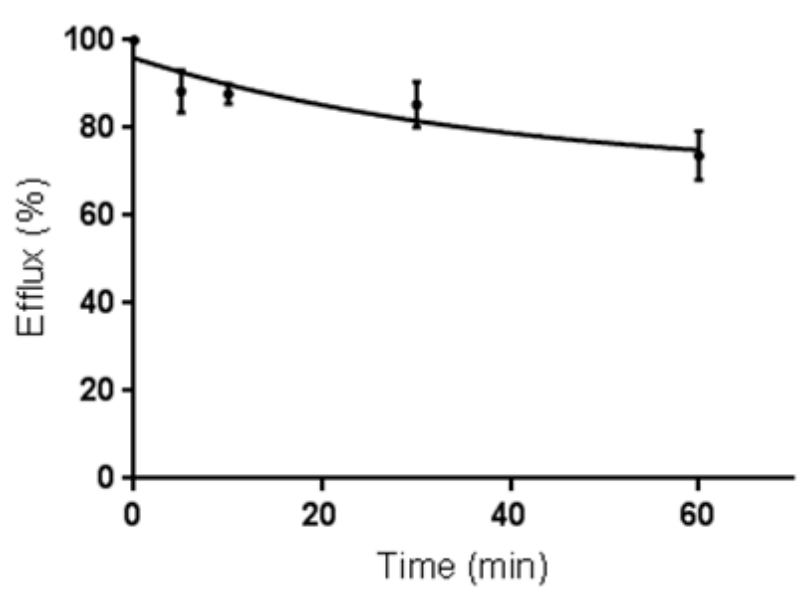

Figure 7. Externalization of ${ }^{68} \mathrm{Ga}-\mathrm{DOTA}-\mathrm{C} 21$ in HT-29 colorectal cancer cell line at different time points $(n=3$, mean $\pm \mathrm{SD})$.

\subsection{PET Imaging and Biodistribution}

HT29 tumour-bearing mice were injected i.p. with ${ }^{68} \mathrm{Ga}$-DOTA-C21 and PET/CT imaging was taken $1 \mathrm{~h}$ and $2 \mathrm{~h}$ post injection (Figure 8). The following day, the same cohort of mice was injected i.v. with ${ }^{68} \mathrm{Ga}$-DOTA-C21 and dynamic PET/CT imaging was registered for the first $10 \mathrm{~min}$ to assess initial distribution of the tracer. The $1 \mathrm{~h}$ post injection time point was retaken to evaluate potential differences in the biodistribution pathway related to the type of injection. Mice were sacrificed at $1.5 \mathrm{~h}$ post injection, and ex-vivo biodistribution performed. As per PET/CT imaging analysis, upon i.v. injection, ${ }^{68} \mathrm{Ga}$-DOTA-C21 was taken up rapidly in the heart and liver, and began accumulating into the tumour within the first minute of circulation. The tumour was immediately visible over background (muscle). At $1 \mathrm{~h}$ post injection, tumour accumulation of the tracer was $2.27 \pm 0.85 \% \mathrm{ID} / \mathrm{cc}(n=3)$ with a tumour to muscle ratio $(\mathrm{T} / \mathrm{M})$ of $1.91 \pm 0.47(n=3) .{ }^{68} \mathrm{Ga}$-DOTA-C21 appeared to have both renal and hepatic clearance. Radioactivity in the heart, which reflected the blood pool, was surprisingly high at $1 \mathrm{~h}$ post injection ( $5.8 \pm 0.7 \% \mathrm{ID} / \mathrm{cc}, n=3)$. Similar biodistribution was observed when the tracer was delivered i.p. At $1 \mathrm{~h}$ post injection, the tumour had an uptake of $1.89 \pm 0.45 \% \mathrm{ID} / \mathrm{cc}(n=5)$ and a T/M of $3.59 \pm$ $2.76(n=5)$. At $2 \mathrm{~h}$ post injection, tumour uptake increased to $2.60 \pm 0.27 \% \mathrm{ID} / \mathrm{cc}(n=5)$ which was reflected by an increase in the T/M to $5.41 \pm 3.62(n=5)$ (Figure 9 and Figure S12A-C). It is worth noting that, when analysing tumour uptake in each single animal, there was no appreciable variation between $1 \mathrm{~h}$ and $2 \mathrm{~h}$ post injection in animals with an initial low tumour uptake. On the contrary, animals with a tumour uptake greater than $4 \% \mathrm{ID} / \mathrm{cc}$ after one hour, tended to accumulate more radiotracer (Figure S12D). No correlation was found between T/M ratio and tumour size (Figure S12E). Ex-vivo biodistribution confirmed the described accumulation (Figure 9). Tumour uptake was $3.08 \pm$ $0.53 \% \mathrm{ID} / \mathrm{cc}(n=5)$ with a T/M of $2.29 \pm 0.62(n=5)$. As already observed by PET, clearance occurred via both renal and hepatobiliary excretion, bone uptake was barely detectable over background and no significant radioactivity was seen in the intracranial region, suggesting that ${ }^{68} \mathrm{Ga}-\mathrm{DOTA}-\mathrm{C} 21$ is unlikely to cross an intact blood-brain barrier. Blood radioactivity was high, suggesting that a high amount of the radiotracer was in circulation or bound to blood constituents such as serum albumin. Further studies evaluating the clearance mechanism of ${ }^{68}$ Ga-DOTA-C21 are underway to understand the high blood circulation, however one explanation may be that ${ }^{68} \mathrm{Ga}-\mathrm{DOTA}-\mathrm{C} 21$ pharmacokinetics follow a two-compartment model $[20,21]$. 


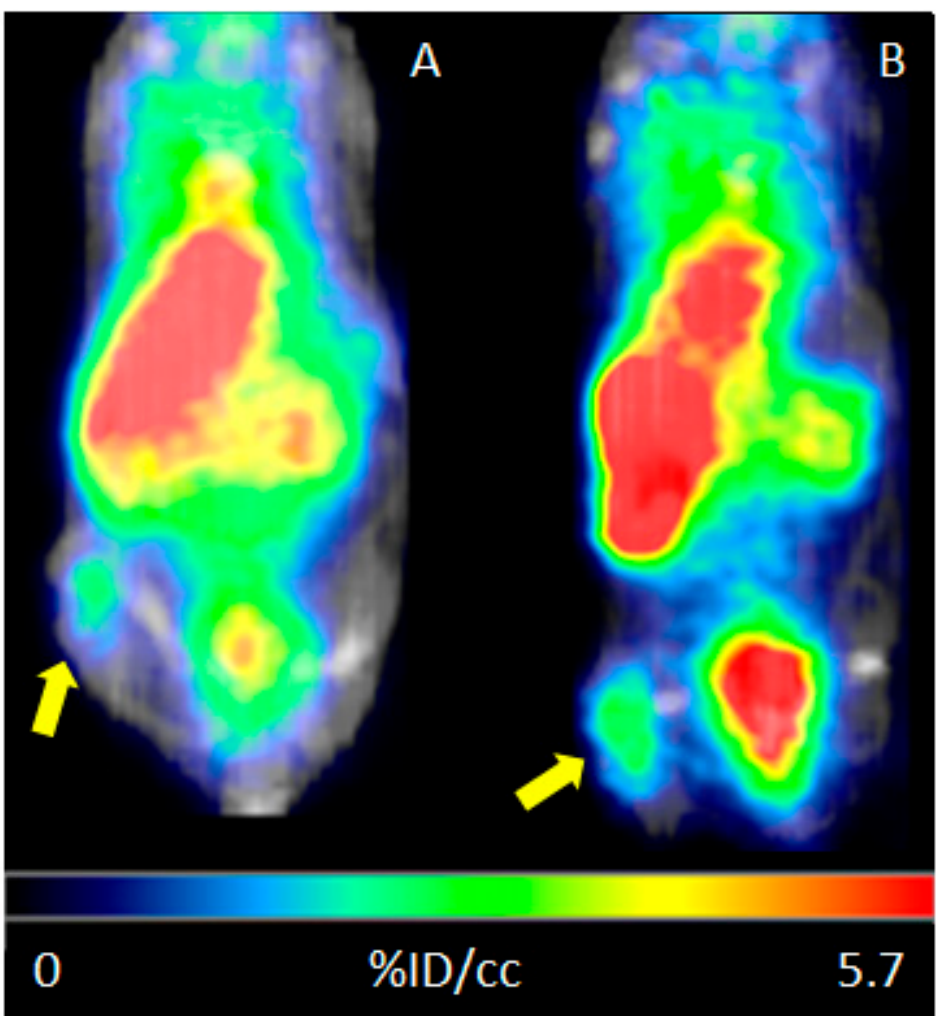

Figure 8. Representative microcoronal-PET/CT scans of HT29 colorectal tumour bearing mouse at $60 \mathrm{~min}(\mathbf{A})$ and $120 \mathrm{~min}$ (B) post i.p. injection of ca. $37 \mathrm{MBq}$ of ${ }^{68} \mathrm{Ga}-\mathrm{DOTA}-\mathrm{C} 21$.
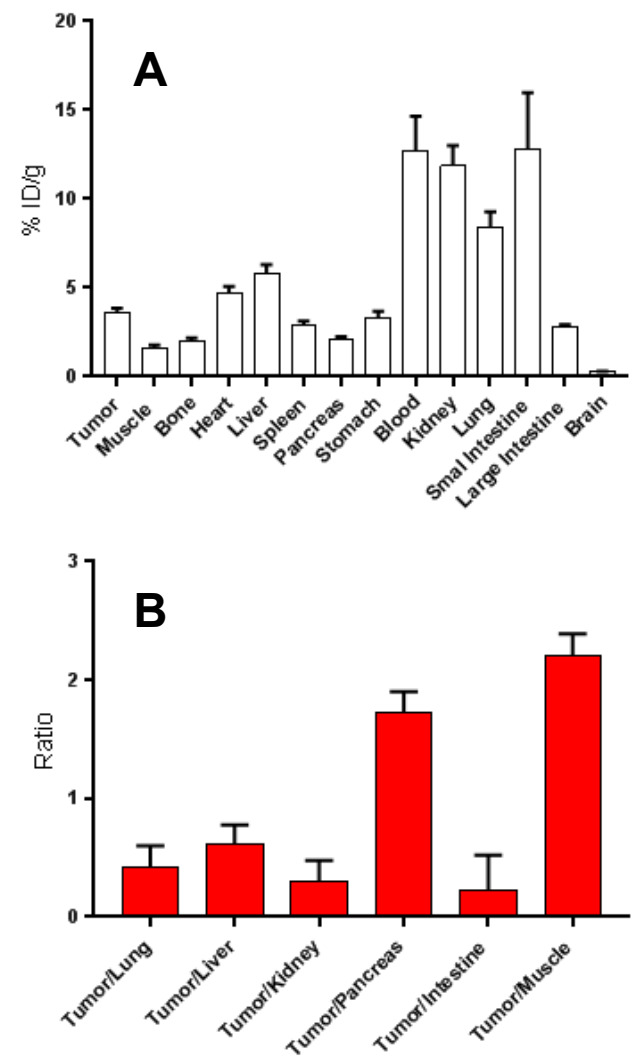

Figure 9. Biodistribution in multiple organs of ${ }^{68}$ Ga-DOTA-C21 in HT-29 colorectal cancer bearing nude mice $(n=5$, mean $\pm \mathrm{SD}$ ) at 90 min post i.v. injection. (A). Ratios of the tumour uptake to major organs $\left(n=5\right.$, mean $\pm \mathrm{SD}$ ) for ${ }^{68} \mathrm{Ga}-\mathrm{DOTA}-\mathrm{C} 21$ at $90 \mathrm{~min}$ post i.v. injection (B). 


\subsection{Metabolism}

Mouse blood was drawn 1.25-1.5 h post injection, processed and analysed by radio-HPLC. Out of the two isomers present in the parent compound, one disappears in the blood and only the more polar one $(\mathrm{Rt}=7.7 \mathrm{~min})$ persists in all the analysed mice $(n=5)$ (Figure S13). It is likely that physiological media influence the keto-enol tautomerism of ${ }^{68} \mathrm{Ga}-\mathrm{DOTA}-\mathrm{C} 21$, stabilizing the diketo form [18].

\section{Discussion}

The use of curcumin and its derivatives as potential therapeutics in many medical applications has been largely attested by a long list of scientific literature [22-24]. We previously demonstrated that ${ }^{68} \mathrm{Ga}$-labelled curcumin complexes had preferential accumulation in HT29 colorectal cancer cells compared to other cancer cell lines and lymphocyte cultures [15]. However, the stability of these complexes in blood was low as the curcuminoid backbone was directly linked to the radio-metal through the keto-enol moiety, resulting in positively charged 2:1 ligand to metal ratio complexes. The present study is focused on evaluating whether a suitable curcumin derivative that is more stably labeled with gallium-68 provides a radiotracer that preferentially accumulates in CRC lesions, and could be a useful early detection agent which enables nuclear medicine imaging techniques. CRC is globally the third most common type of cancer and is usually diagnosed by invasive techniques like sigmoidoscopy or colonoscopy, during which a colon specimen is collected. These procedures are then followed by medical imaging (usually CT scan) to determine if the disease has spread. While small polyps may be removed during colonoscopy, the cancerous state of large polyps may be assessed by a biopsy [25]. The introduction of a PET radiotracer that specifically accumulates in CRC might be useful for verifying the nature of these lesions without resort to invasive methods. Moreover, treatments used for colorectal cancer may include some combination of surgery, radiation therapy, chemotherapy and targeted therapy and nuclear medicine imaging may be a suitable technique to stage and assess follow-up of the patients.

In the present study, the structure of the first generation of gallium-68 curcumin complexes has been improved by adding DOTA, a strong gallium-68 chelator. DOTA was linked through an (amino)ethyl spacer to one of the phenol groups of the curcumin backbone. With the addition of DOTA, the new bio-conjugate (namely DOTA-C21) has an enhanced water solubility and a higher stability of the complex with gallium-68 is achieved in physiological conditions. Despite its solubility in water, ${ }^{1} \mathrm{H}-\mathrm{NMR}$ spectrum of DOTA-C21 in $\mathrm{D}_{2} \mathrm{O}$ (Figure S2A) exhibited extremely broad signals in the aromatic region, suggesting that the hydrophobic backbone of curcumin interacted strongly by intramolecular $\pi-\pi$ stacking. The signals could be sharpened by reducing the solvent polarity, for example, switching to methanol- $\mathrm{d}_{4}$, which reduced aggregation. The ${ }^{1} \mathrm{H}-\mathrm{NMR}$ spectrum in methanol- $d_{4}$ (Figure S2B) provided signals in the aromatic region attributable to the asymmetric curcumin moiety of DOTA-C21, while methylene signals of the ethyl spacer and DOTA were found in the aliphatic region (3-4.5 ppm). The structure of curcumin in DOTA-C21 is asymmetric due to the alkylation of one phenol group with the (amino)ethyl spacer, as clearly shown by two slightly shifted spin systems with equivalent spectral pattern (Figures S2, S3). Complete assignment and chemical structure with atom numbering is reported in Section 4.1.1.

As shown in the ESI-LC-MS analysis (Figure S1), DOTA-C21 was present in two isomeric forms that could be assigned to the keto-enol and di-keto tautomer, respectively $[17,18]$. As the equilibrium was influenced by solvent polarity and $\mathrm{pH}$, the ratio between the two forms could vary over the different analysis conditions. Due to the rapid interconversion between the two isomeric forms also in physiological conditions, it was not expected that the two isomers exhibited different in vivo properties but this assumption should be verified with further studies.

When Ga-DOTA-C21 complexes were synthesized mimicking the radiolabelling experimental conditions $\left(95^{\circ} \mathrm{C}, 30 \mathrm{~min}, \mathrm{~L}: \mathrm{M}\right.$ 1.5:1, $0.4 \mathrm{M} \mathrm{NH}_{4} \mathrm{Ac}$ ), complex formation was confirmed by mass spectrometry and two compounds with the same $m / z$, corresponding to gallium-DOTA-C21 complexes at 1:1 metal to ligand molar ratio, were identified by ESI-LC/MS (Figure S4). The isotopic pattern 
(dashed square, Figures S4C and S5) highlighted the presence of gallium with its characteristic isotopic distribution in both compounds. Further LC/MS fragmentation experiments were carried out in order to exclude the involvement of the keto-enol moiety in the coordination sphere. As reported in Figure 3, the fragmentation pattern of the two isobaric peaks (panels B and C) were completely equivalent and could be attributed to cleavage of the curcumin structure, while gallium was always strongly bound by DOTA (Figure 10). This finding supported the hypothesis that the two isobaric peaks were due to the keto-enol and di-keto tautomers and not to different coordination modes.

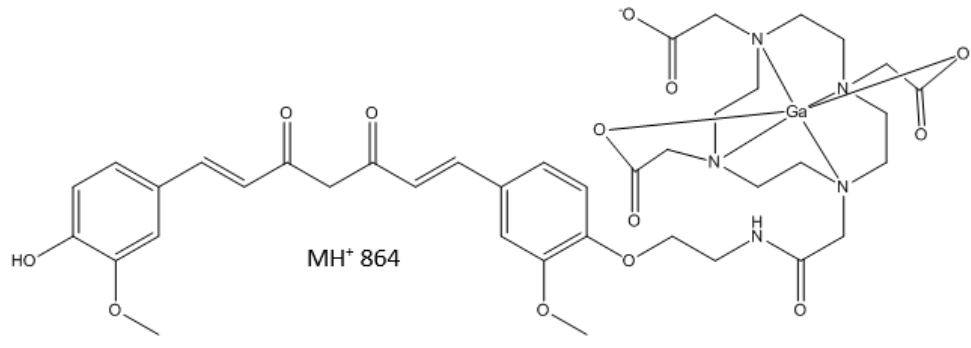

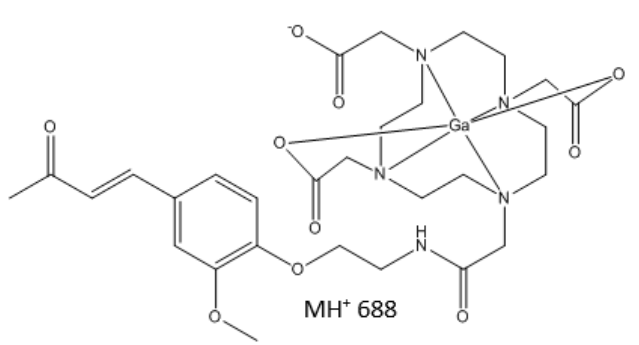<smiles>C=C/C=C/c1ccc(OCCNC(=O)CN2CCN(CC(=O)O)CC2N2CCN(CC(=O)O)CC2N2CCN(CC(=O)O)CC2)c(OC)c1</smiles><smiles>C=Cc1ccc(OCCNC(=O)CN2CCN(CC(=O)O)CC23CCN(CC(=O)O)CCN3CC(=O)O)c(OC)c1</smiles><smiles>C=CNC(=O)CN1CCN(CC(=O)OCC(=O)O)CC12CN(CC(=O)O)CCN2CC(=O)O</smiles>

Figure 10. Molecular fragments of Ga-DOTA-C21 attributed to the correspondent $m / z$ signals detected in panel B and C of Figure 3.

To elucidate chelation mode and binding sites in depth, ${ }^{1} \mathrm{H}-\mathrm{NMR}$ titration of DOTA-C21 with $\mathrm{Ga}^{3+}$ was performed in methanol- $\mathrm{d}_{4}$ at $25{ }^{\circ} \mathrm{C}$ (Figure S6). The signals at $3.2 \mathrm{ppm}$ (methylene groups of tetraazacyclododecane) and at $3.87 \mathrm{ppm}$ (methylene groups in $\alpha$ to carboxylic groups) in the free ligand broadened and shifted at the first $\mathrm{Ga}^{3+}$ addition, suggesting the involvement of the chelator in gallium coordination. A complete overview of 1:1 metal to ligand molar ratio complex formation for both proton and carbon resonances was shown by the overlap of ${ }^{1} \mathrm{H}-{ }^{13} \mathrm{C}-\mathrm{HSQC}-\mathrm{NMR}$ spectra of the free ligand (DOTA-C21) and its gallium complex (Ga-DOTA-C21) (Figure 2). The metal coordination induces a de-shielding effect on all methylene groups of the chelator ring resulting in an increase of both proton and carbon chemical shifts. Particularly, metal complexation removes chemical shift equivalence of ring methylene protons, as clearly showed by ${ }^{1} \mathrm{H}-,{ }^{1} \mathrm{H}-\mathrm{COSY}$ and ${ }^{1} \mathrm{H}-{ }^{13} \mathrm{C}-\mathrm{HSQC}-\mathrm{NMR}$ spectra (Figure S7 and Figure 4). Methylene group $\mathrm{r}_{1}$ shifts from ${ }^{1} \mathrm{H} /{ }^{13} \mathrm{C} \delta(\mathrm{ppm}) 3.35 / 49.77$ to 4.00/54.65 and 3.38/54.65, respectively. A lower shift is observed for methylene group $r_{2}$ from ${ }^{1} \mathrm{H} /{ }^{13} \mathrm{C} \delta$ (ppm) 3.26/49.64 to 3.47/57.11 and 3.41/57.11, respectively. These outcomes suggest the assignment of type $r_{1}$ to those methylene groups in $\alpha$ position to carboxylic moiety directly involved in metal coordination (atom numbering 17, 18, 21 and 22). All atom numbering herein reported refers 
to Figures 11 and 12), while $r_{2}$ type can be attributed to those methylene groups in $\alpha$ position to non-coordinating carboxylic (amidic) moiety (atom numbering 16, 19, 20 and 23). Methylene groups of the carboxylic arms in $\alpha$ to both nitrogen and carboxylic (amidic) moiety undergo the effect of metal coordination in a different way if the carboxylic group is involved in coordination or not. As shown in Figure 4, methylenes of the carboxylic arms shift from ${ }^{1} \mathrm{H} /{ }^{13} \mathrm{C} \delta(\mathrm{ppm}) 3.75-3.87 / 54.20$ to 3.83/59.41, $3.79 / 60.64$ and 3.74/61.68, respectively. Conversely, the chemical shifts of the ethyl spacer (H12 and H13) are unaffected by metal coordination.

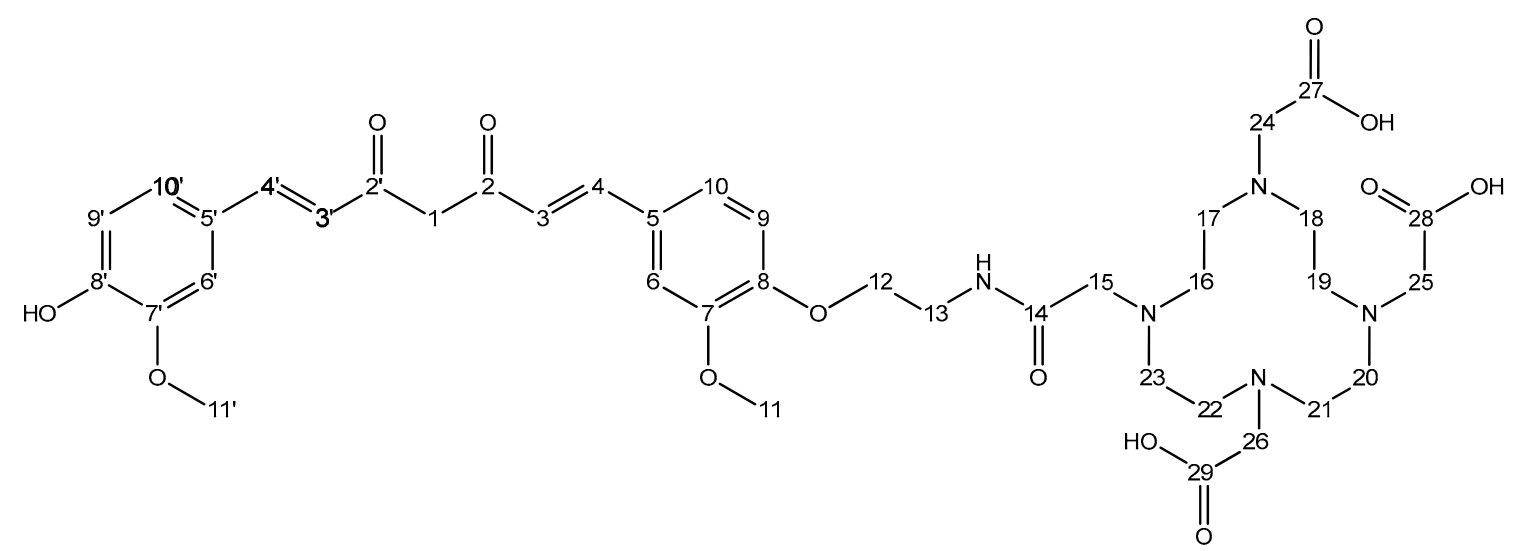

Figure 11. Chemical structure of DOTA-C21 with atom numbering.

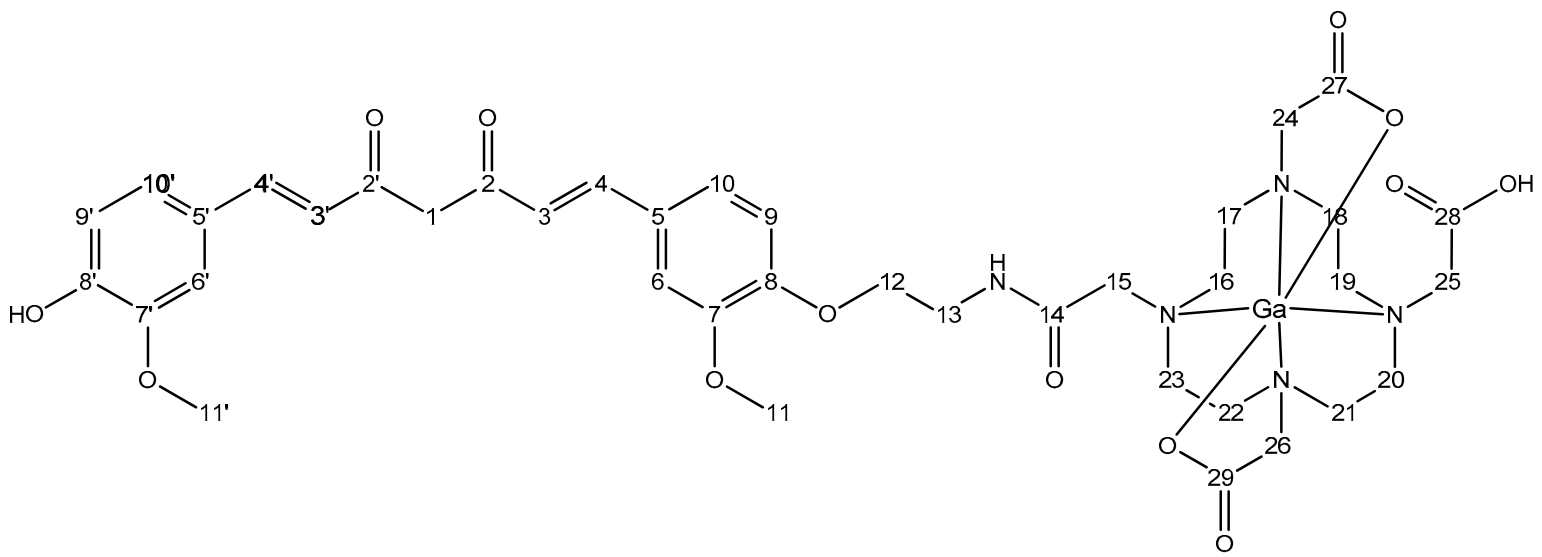

Figure 12. Chemical structure of Ga-DOTA-C21 with atom numbering.

Curcumin and curcuminoids act as fluorophores in the visible spectrum with strong solvent dependence, and consequently may be employed as fluorescent probes for distribution studies in cells and tissues. The typical main absorbance, due to the keto-enol group, was around $420 \mathrm{~nm}$ and the emission was around $500 \mathrm{~nm}$, when excited at $420 \mathrm{~nm}$ wavelength [14]. In particular, the absorption of DOTA-C21 showed a maximum at $410 \mathrm{~nm}$ in water solution. When a titration with $\mathrm{Ga}^{3+}$ was performed, no variations were observed at $\lambda_{\max }$ suggesting that the keto-enol moiety was not involved in gallium complexation. On the other hand, an increase in absorbance around $300 \mathrm{~nm}$ upon metal addition was detected, supporting that DOTA was the main moiety involved in metal chelation (Figure S9). The free ligand showed weak fluorescence emission upon excitation at $\lambda_{\max }(410 \mathrm{~nm})$ with a maximum at $525 \mathrm{~nm}$ (Figure S10). These results differ from previously reported curcumin studies. In fact, while fluorescence quenching occurred due to gallium chelation by the keto-enol moiety [14], herein, emission spectra of DOTA-C21 were only slightly affected by gallium addition. This opposite behaviour furthermore confirmed the involvement of DOTA in gallium chelation rather than the keto-enol group, confirming what was seen by MS and NMR analyses. 
Initially, DOTA-C21 was labelled with gallium-68 by preprocessing the generator elution by cation exchange purification [26]. This resulted in efficient labelling with high RCY and RCP after 5 min of incubation of just $10 \mathrm{nmol}$ of precursor. In order to simplify the procedure, labelling was also attempted without preprocessing of the generator elutions. In these conditions, labelling was less effective, further purification of the final product was necessary due to the presence of high amounts of hydrolysed products, and $80 \mathrm{nmol}$ of precursor was needed to drive the reaction to completion. This behavior could be ascribed to the presence of high levels of metal impurities that come from the generator and potentially compete with gallium-68 in the coordination with DOTA [19]. It is worth noting, that DOTA is known to have slow kinetics of complexation and requires harsh conditions for labelling. For these reasons, use of DOTA as a chelator for gallium-68 may enhance hydrolysis of the product and decomposition of the precursor. Use of chelators with smaller cavities such as NOTA and derivatives, or some acyclic chelators recently reported in literature such as HBED-CC or THP, would likely resolve these problems [27].

Similar to other gallium-68 labelled curcuminoid derivatives reported in literature [15] but differently from ${ }^{68} \mathrm{GaCl}_{3},{ }^{68} \mathrm{Ga}$-DOTA-C21 exhibited a time-dependent uptake in HT29 cells suggesting a relationship between the curcumin-like structure and the ability of the cells to bind and internalize the radiotracers. In particular, the addition of a specific chelator connected to a phenolic moiety appears to be advantageous for the internalization of the compound when compared to the our previously reported tracers where the keto-enol group was exploited to form gallium-68 complexes [15]. Once internalized or bound to the cell membrane, ${ }^{68} \mathrm{Ga}$-DOTA-C21 showed a slow efflux rate and $75 \%$ of the compound was still retained by the cells after $60 \mathrm{~min}$ of incubation. The mechanism by which curcumin or its derivatives are taken up in colorectal tumours has not been elucidated so far. It has been reported that curcumin has a structure suitable to bind nuclear vitamin $\mathrm{D}$ receptor and plays a role in colon cancer chemoprevention thanks to this property $[28,29]$ but no specific experiments have been performed by the authors to confirm this finding. To test the hypothesis of VDR-mediated curcumin uptake, we analysed the VDR expression in HT29 cells and we found that this expression was higher than in other tumour cell lines and human lymphocytes. Then, to assess VDR-specificity, calcitriol, the hormonally active metabolite of vitamin D and VDR natural ligand, was used as a blocking agent. This would clarify the potential involvement of these receptors in ${ }^{68} \mathrm{Ga}$-DOTA-C21 uptake. Unfortunately, uptake of ${ }^{68} \mathrm{Ga}$-DOTA-C21 was not influenced by the presence of the excess of calcitriol (Figure $6 \mathrm{C}$ ) therefore providing evidence that curcumin and calcitrol are not competitive substrates for the same binding site on VDR. In conclusion, seeing as this is a topic of great interest, further studies are necessary to evaluate the cellular uptake mechanism of curcumin and its radiolabelled derivatives. When the mechanism of accumulation will be elucidated, considerations about the structure-affinity of ${ }^{68}$ Ga-DOTA-C21 in comparison to other compounds will be possible.

The stability tests in whole blood (Figure 7) attested to a certain lability of the curcumin backbone that was probably partially metabolized into more polar products, which then underwent renal excretion in physiological conditions, as proved during the biodistribution study (kidney uptake 11.86 $\pm 1.1 \% \mathrm{ID} / \mathrm{g}$ at $1.5 \mathrm{~h}$ post injection). However, it was shown that $57 \pm 3 \%$ of ${ }^{68} \mathrm{Ga}$-DOTA-C21 complexes remained intact after $120 \mathrm{~min}$ of incubation in human blood, comparing favourably with our other previously reported gallium-68 complexes [14], where the metal, coordinated by the keto-enol moiety, was rapidly released. Stability of ${ }^{68} \mathrm{Ga}$-DOTA-C21 in mouse blood appears comparable, if not superior, to previously reported F-18 labelled curcumin derivatives where the amount of unchanged radiotracer in rat plasma after $10 \mathrm{~min}$ post injection comprised only $45 \%$ of the total injected radioactivity [30]. ${ }^{68}$ Ga-DOTA-C21 exhibited a slow absorption rate into the main organs and a high amount of activity $(12.73 \pm 1.9 \% \mathrm{ID} / \mathrm{g})$ was recorded in blood after $1.5 \mathrm{~h}$ post injection suggesting a strong binding interaction with serum albumin as reported for curcumin and their derivatives in general $[30,31]$. Significant uptake of ${ }^{68} \mathrm{Ga}$-DOTA-C21 occurred in the intestine $(13.56 \pm 3.3 \% \mathrm{ID} / \mathrm{g})$, lungs $(8.42$ $\pm 0.8 \% \mathrm{ID} / \mathrm{g})$, liver $(5.81 \pm 0.5 \% \mathrm{ID} / \mathrm{g})$ and heart $(4.70 \pm 0.4 \% \mathrm{ID} / \mathrm{g}) .{ }^{68} \mathrm{Ga}-\mathrm{DOTA}-\mathrm{C} 21$ rapidly accumulated in colorectal xenograft tumours with an uptake of $3.57 \pm 0.3 \% \mathrm{ID} / \mathrm{g}$ after $1.5 \mathrm{~h}$ post 
injection. Compared to previously reported ${ }^{18} \mathrm{~F}$-labelled curcumin derivatives, which exhibit fast clearance from the blood to the liver and fast hepatobiliary excretion to the intestine, ${ }^{68} \mathrm{Ga}$-DOTA-C21 blood clearance was slow and it showed both renal and hepatobiliary excretion. Generally, higher kidney and lower intestine uptake with respect to the fluorinated compounds were found. However, the amount of radiotracer accumulated in the intestine might still be a concern since it could mask the colorectal cancer uptake in a potential human examination. Liver uptake was comparable, indicating that ${ }^{68} \mathrm{Ga}$-DOTA-C21 remained partially metabolised, likely via hexahydrocurcumin-glucuroniside conjugation route. Similar to ${ }^{18}$ F-radiolabelled compounds, brain uptake was almost negligible [30,32].

\section{Materials and Methods}

\subsection{General Procedures and Chemicals}

All chemicals were reagent grade and used without further purification unless otherwise specified.

Complete information related to general laboratory procedures and instrumental analyses are reported in the Supplementary Information file.

4.1.1. Synthesis of 1,4,7,10-tetraazacyclododecane -1,4,7,10-tetraacetic (1,7-bis(4-hydroxy-3-methoxyphenyl)- 1,6-heptadiene-3,5-dione (DOTA-C21)

An anhydrous DMF (4 mL) solution of curcumin $(100 \mathrm{mg}, 0.27 \mathrm{mmol})$ and potassium carbonate (45 mg, $0.33 \mathrm{mmol}$ ) was added to 2-(Boc-amino)ethyl bromide ( $61 \mathrm{mg}, 0.27 \mathrm{mmol})$. The mixture was stirred for $48 \mathrm{~h}$ at room temperature and then concentrated under reduced pressure. The residue was purified by flash silica-gel column chromatography ( $2 \%$ methanol/dichloromethane) to obtain compound $1(16 \mathrm{mg}, 12 \%)$ as a red-solid. ${ }^{1} \mathrm{H}-\mathrm{NMR}\left(600 \mathrm{MHz}, \mathrm{CDCl}_{3}\right) \delta 1.45(\mathrm{~s}, 9 \mathrm{H}), 3.54-3.62(\mathrm{~m}, 2 \mathrm{H}), 3.90(\mathrm{~s}, 3 \mathrm{H})$, $3.95(\mathrm{~s}, 3 \mathrm{H}), 4.08-4.12(\mathrm{~m}, 2 \mathrm{H}), 5.16-5.18(\mathrm{~m}, 1 \mathrm{H}), 5.79(\mathrm{~s}, 1 \mathrm{H}), 5.85(\mathrm{~s}, 1 \mathrm{H}), 6.49(\mathrm{dd}, 2 \mathrm{H}, J=6.0,16.00 \mathrm{~Hz})$, $6.92(\mathrm{dd}, 2 \mathrm{H}, J=8.0,15.6 \mathrm{~Hz}), 7.10(\mathrm{ddd}, 4 \mathrm{H}, J=2.0,5.6,22.4 \mathrm{~Hz}), 7.60(\mathrm{~d}, 2 \mathrm{H}, J=16.0 \mathrm{~Hz})$.

An anhydrous dichloromethane $(2.4 \mathrm{~mL})$ solution of $\mathbf{1}(10.6 \mathrm{mg}, 0.02 \mathrm{mmol})$ was added to TFA $(0.6 \mathrm{~mL})$. The mixture was sonicated for $20 \mathrm{~min}$ and then concentrated under reduced pressure. The residue was dissolved in DMF ( $3 \mathrm{~mL})$ and diisopropylethylamine $(21 \mu \mathrm{L}, 0.12 \mathrm{mmol})$ and DOTA-NHS ester (19 mg, $0.025 \mathrm{mmol}$ ) were added. The mixture was stirred overnight at room temperature, and then concentrated under reduced pressure. The residue was purified by flash silica-gel column chromatography (20-40\% acetonitrile/water containing 0.1\% TFA) and freeze-dried to obtain 2 (10 mg, $38.5 \%$ ) as a yellow-red colour solid. MS (ESI) $m / z 798.4[\mathrm{M}+\mathrm{H}]^{+}$.

${ }^{1} \mathrm{H}-\mathrm{NMR}\left(600 \mathrm{MHz}, \mathrm{MeOD}-\mathrm{d}_{4}\right.$ ) 8: 3.2-3.3 (H16 $\rightarrow \mathrm{H} 23$, m broad, 16H), 3.87 (H15/H24/H25/H26, $\mathrm{m}$ broad, $8 \mathrm{H}), 3.65(\mathrm{H} 13, \mathrm{t}, 2 \mathrm{H}), 3.93\left(\mathrm{H} 11^{\prime}, \mathrm{s}, 3 \mathrm{H}\right), 3.94(\mathrm{H} 11, \mathrm{~s}, 3 \mathrm{H}), 4.17(\mathrm{H} 12, \mathrm{t}, 2 \mathrm{H}), 6.00(\mathrm{H} 1, \mathrm{~s}, 1 \mathrm{H})$, $6.66\left(\mathrm{H} 4^{\prime}, \mathrm{d}, 1 \mathrm{H}\right), 6.70(\mathrm{H} 4, \mathrm{~d}, 1 \mathrm{H}), 6.85\left(\mathrm{H}^{\prime}, \mathrm{d}, 1 \mathrm{H}\right), 7.05(\mathrm{H9}, \mathrm{d}, 1 \mathrm{H}), 7.14\left(\mathrm{H} 10^{\prime}, \mathrm{dd}, 1 \mathrm{H}\right), 7.22(\mathrm{H} 10$, $\mathrm{dd}, 1 \mathrm{H}), 7.24\left(\mathrm{H6}^{\prime}, \mathrm{d}, 1 \mathrm{H}\right), 7.29(\mathrm{H} 6, \mathrm{~d}, 1 \mathrm{H}), 7.61\left(\mathrm{H} 3^{\prime}, \mathrm{d}, 1 \mathrm{H}\right), 7.62(\mathrm{H} 3, \mathrm{~d}, 1 \mathrm{H}) .{ }^{13} \mathrm{C}-\mathrm{NMR}(150.9 \mathrm{MHz}$,

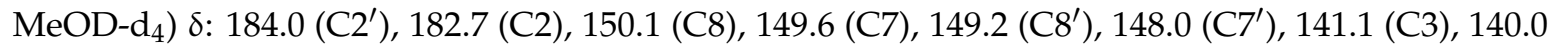
$\left(\mathrm{C}^{\prime}\right), 128.8(\mathrm{C} 5), 127.1\left(\mathrm{C}^{\prime}\right), 122.8\left(\mathrm{C} 10^{\prime}\right), 122.5$ (C10), $122.0(\mathrm{C} 4), 120.8\left(\mathrm{C}^{\prime}\right), 115.2\left(\mathrm{C}^{\prime}\right), 113.0(\mathrm{C} 9)$, 110.4 (C6/C6'), 100.7 (C1), 67.0 (C12), 55.2 (C11'), 55.1 (C11), 54.4 (C15), 54.1 (C24/C25/C26), 50.0 $(\mathrm{C} 16 \rightarrow \mathrm{C} 23), 38.6$ (C13). Atom numbering refers to Figure 11.

\subsubsection{Preparation of ${ }^{\text {nat }}$ Ga-DOTA-C21 Complexes}

Compound 2 was dissolved in $0.4 \mathrm{M}$ ammonium acetate ( $450 \mu \mathrm{g}$ of ligand in $600 \mu \mathrm{L}$ of buffer, $\mathrm{pH} 4.5)$ and stirred at $95{ }^{\circ} \mathrm{C}$ for $5 \mathrm{~min}$. Then, $85 \mu \mathrm{L}$ of $10 \mathrm{mM} \mathrm{Ga}\left(\mathrm{NO}_{3}\right)_{3} \cdot 9 \mathrm{H}_{2} \mathrm{O}$ solution were added to the mixture in order to have a 1.5:1 metal to ligand molar ratio. The advancement of the complexation reaction was monitored by ESI-LC-MS. Reaction was completed after $30 \mathrm{~min}$ of heating $(m / z$ 864.2-866.2). Complete data on chemical characterization of DOTA-C21 and its gallium complexes are reported in the supplementary material (Figures S1-S10). 


\subsection{Radiolabelling of DOTA-C21 with Gallium-68}

Postprocessing based labelling protocol: ${ }^{68} \mathrm{Ge} /{ }^{68} \mathrm{Ga}$ generator (EZAG, Berlin, Germany) was eluted with $5 \mathrm{~mL} 0.1 \mathrm{M} \mathrm{HCl}$ and gallium-68 was passed and fixed on a AG50W-X4, 200-400mesh hydrogen form, cartridge (Bio-Rad, Milan, Italy). Gallium-68 was eluted with $0.4 \mathrm{~mL}$ of a 97.56\% acetone, $0.05 \mathrm{M} \mathrm{HCl}$ solution and an aliquot $(80 \mathrm{MBq})$ was added to a vial containing $10 \mathrm{nmol}$ of DOTA-C21 in a $0.2 \mathrm{M}$ ammonium acetate solution ( $\mathrm{pH} 4$ ). The mixtures were incubated at $95{ }^{\circ} \mathrm{C}$ and kinetic studies were performed at 1,3,5, 10 and 20 min by TLC analysis.

Direct labelling protocol: ${ }^{68} \mathrm{Ge} /{ }^{68} \mathrm{Ga}$ generators were manually eluted with $4 \mathrm{~mL}$ of $\mathrm{HCl}$ solution (0.1 N or $0.05 \mathrm{~N}$ depending whether EZAG or ITG generator was used, respectively). $700 \mu \mathrm{L}$ of eluates, containing around $200 \mathrm{MBq}$ of gallium-68, were collected in a disposable vial containing $80 \mathrm{nmol}$ of precursors and $65 \mu \mathrm{L}$ of a $1.5 \mathrm{M}$ sodium acetate in order to maintain the $\mathrm{pH}$ of the reaction around 4 . The mixture was heated at $95^{\circ} \mathrm{C}$ up to $10 \mathrm{~min}$ and consequently passed through a light $\mathrm{C} 18$ cartridge (Waters, Milan, Italy) to eliminate unlabelled gallium-68 and polar by-products. The cartridge was washed with $3 \mathrm{~mL}$ of saline and $1 \mathrm{~mL}$ of $10 \%$ ethanol solution and then eluted with $1 \mathrm{~mL}$ of $95 \%$ ethanol solution followed by $2 \mathrm{~mL}$ water. Aliquots of the crude mixture and of the final product after purification were collected to assess the radiochemical purity of the product (RCP) by UHPLC analysis. Every preparation was performed at least in triplicate and all the incorporation yields were computed by considering the radiochemical purity (RCP) obtained from the UHPLC or TLC analyses.

\subsection{In Vitro Stability Studies}

For assessing the stability, aliquots of ${ }^{68} \mathrm{Ga}-\mathrm{DOTA}-\mathrm{C} 21$ solution $(1 \mathrm{~mL}$, approx. $5 \mathrm{nmol}, 37 \mathrm{MBq})$ were incubated with $1 \mathrm{~mL}$ of i) PBS $(0.2 \mathrm{M} \mathrm{pH}=7.2)$, ii) human serum (HS), iii) human whole blood (HB) at $37^{\circ} \mathrm{C}$ for different time points $(10,40,70,120 \mathrm{~min})$. Samples incubated with HB were centrifuged at $3000 \mathrm{rpm}$ for $10 \mathrm{~min}$ to precipitate the blood cells and a solution $(200 \mu \mathrm{L})$ of $\mathrm{ACN} / \mathrm{H}_{2} \mathrm{O} / \mathrm{TFA} 50 / 45 / 5$ $v / v / v$ was added to $400 \mu \mathrm{L}$ of the supernatant. Samples incubated with HS were treated only with $\mathrm{ACN} / \mathrm{H}_{2} \mathrm{O} / \mathrm{TFA} 50 / 45 / 5 v / v / v$ solution. After another centrifugation under the same conditions, the supernatant was injected into an UPLC for assessing the stability of the preparation.

\subsection{Cell Culture and Animal Models}

HT29 (colorectal adenocarcinoma) cells were kindly provided by Dr Alessandro Zerbini from the Unit of Infectious Diseases and Hepatology, Azienda Ospedaliero-Universitaria di Parma (Parma, Italy). The cells were grown in DMEM $+10 \%$ FBS supplemented with penicillin and streptomycin at $37^{\circ} \mathrm{C}$ in a $5 \% \mathrm{CO}_{2}$ incubator. To determine protein yield, cells were lysed with a radio immune-precipitation assay (RIPA) buffer (Santa Cruz Biotechnology) and protein concentration was determined with the detergent compatible (DC) protein assay (Bio-Rad) following the manufacturer's instructions using bovine serum albumin as protein standard.

All animal experiments were performed in compliance with the guidelines for the care and use of research animals established by The University of Texas MD Anderson Cancer Center (ethic approval number 1179). Mice were maintained in sterile conditions and could eat and drink ad libitum. Mice were housed in a $12 \mathrm{~h}$ light-dark cycle. Adult female mice (athymic nude, Taconic Biosciences, 7-8 weeks old) were injected subcutaneously with $9 \times 10^{6}$ HT29 cells in 50\% matrigel on the right flank.

\subsection{In Vitro Uptake, Internalization and Efflux in Colorectal Cancer Cell Line}

Cellular uptake, internalization, blocking and efflux of ${ }^{68}$ Ga-DOTA-C21 were studied in HT29 colon carcinoma cells. All experiments were performed in triplicate (unless otherwise stated). For uptake studies, HT29 cells were incubated at $37{ }^{\circ} \mathrm{C}$ with $20 \mu \mathrm{L}$ (ca. $2 \mathrm{MBq}, 0.2 \mathrm{nmol}, 0.1 \mu \mathrm{M}$ final concentration) of ${ }^{68} \mathrm{Ga}$-DOTA-C21 and ${ }^{68} \mathrm{GaCl}_{3}$ as a negative control. For blocking experiments HT29 cells were preincubated for $1 \mathrm{~h}$ at $37^{\circ} \mathrm{C}$ with $100 \mu \mathrm{L}$ of $1 \mathrm{mg} / \mathrm{mL}$ calcitriol solution and then with $20 \mu \mathrm{L}$ (ca. $2 \mathrm{MBq}, 0.2 \mathrm{nmol}, 0.1 \mu \mathrm{M}$ final concentration) of ${ }^{68} \mathrm{Ga}$-DOTA-C21. Uptake was stopped after 
5, 10, 30 and 60 min by removing the medium and the cells were washed twice with ice-cold PBS or $0.1 \mathrm{M}$ ( $\mathrm{pH} 2.9$ ) ice-cold glycine solution for discriminating between the total bound activity and the internalized activity, respectively. Finally, the cells were detached with $2 \mathrm{~mL}$ of trypsin/EDTA $0.25 \%$ solution at $37^{\circ} \mathrm{C}$ and centrifuged in order to separate the supernatant from the cells pellet. The radioactivity associated to the pellets was measured in the dose calibrator and normalized for the protein contents. For efflux studies, cells were incubated with $20 \mu \mathrm{L}$ (ca. $2 \mathrm{MBq}, 0.2 \mathrm{nmol}, 0.1 \mu \mathrm{M}$ final concentration) of ${ }^{68} \mathrm{Ga}$-DOTA-C21 for $1 \mathrm{~h}$ at $37^{\circ} \mathrm{C}$. The uptake was stopped by removing the supernatant and cells were washed twice with ice-cold PBS. Then $1 \mathrm{~mL}$ of fresh prewarmed $\left(37^{\circ} \mathrm{C}\right)$ medium was added and cells were newly incubated at $37^{\circ} \mathrm{C}$ for 5, 10, 30, $60 \mathrm{~min}$. After these time points, the media were collected and the radioactivity released from the cells was measured in the dose calibrator.

\subsection{Biodistribution of ${ }^{68} \mathrm{Ga}-\mathrm{DOTA}-\mathrm{C} 21$}

${ }^{68} \mathrm{Ga}$-DOTA-C21 biodistribution was determined in mice bearing HT29 subcutaneous tumour model $(n=5)$ at $1.5 \mathrm{~h}$ post tail vein injection of $3.7 \mathrm{MBq}(1 \mathrm{~mL}, 0.2 \mu \mathrm{M}$ solution $)$ of radiotracer. Blood samples were drawn from the right leg using a femoral vein puncture as well as an intra-cardiac puncture to draw blood from the heart to assess the in vivo stability of the radiotracer. The animals were euthanized using $2 \%$ isoflurane and exsanguinated, and the thoracic cavity opened. Organs were excised, washed with saline, dried with absorbent tissue paper, counted on a gamma-counter (Packard BioScience Cobra II Auto-Gamma, Meriden, USA) and weighed. Organs of interest included: tumour, heart, spleen, lungs, liver, kidneys, stomach, small intestine, large intestine, muscle, bone and brain. The uptake in each organ was calculated as a percentage of the injected dose per gram of tissue (\% ID/g). Blood samples were immediately centrifuged to precipitate the blood cells and a solution $(200 \mu \mathrm{L})$ of $\mathrm{ACN} / \mathrm{H}_{2} \mathrm{O} / \mathrm{TFA} 50 / 45 / 5 v / v / v$ was added to $400 \mu \mathrm{L}$ of the supernatant. After a further centrifugation, the extracted solution was injected into an HPLC.

\subsection{PET Imaging of Tumour Bearing Mice and Analysis}

Mice were briefly anaesthetized ( $<5 \mathrm{~min}$ ) using $1 \%$ to $2 \%$ isoflurane with $\mathrm{O}_{2}$ as a carrier. Mice were injected i.v. or i.p. with ${ }^{68} \mathrm{Ga}$-DOTA-C21 in sterile phosphate-buffered saline (PBS) $(10 \% \mathrm{EtOH}$ or $50 \%$ EtOH respectively) with a target of $3.7 \mathrm{MBq}(1 \mathrm{~mL}, 0.2 \mu \mathrm{M}$ solution) per mouse. Actual injected dose was calculated based on measuring the pre and postinjection activity in the syringe with a dose calibrator (Capintec, Florham Park, NJ, USA). Mice were then returned to their cages, quickly became ambulatory and could move freely, eat and drink ad libitum for $\sim 45 \mathrm{~min}$. Mice were then anaesthetized using 1\% and 3\% isoflurane, transferred to a preclinical PET/SPECT/CT system (Albira PET/SPECT/CT, Bruker, Ettlingen, Germany) and maintained at $0.5 \%$ to $2 \%$ isoflurane with continuous monitoring of respiration during the acquisition. PET images were acquired for $10 \mathrm{~min}$ using a $15 \mathrm{~cm}$ FOV centred on the tumour; CT images were acquired for fusion using a $7 \mathrm{~cm}$ FOV also centred on the tumour. The same procedure was repeated for the $1 \mathrm{~h}$ and $2 \mathrm{~h}$ PET/CT scan. The $10 \mathrm{~min}$ PET/CT dynamic scan was recorded immediately after injection of the tracer, and then mice were allowed to awake and freely move around their cages until the $1 \mathrm{~h}$ time point. Images were reconstructed using MLEM and FBP for PET and CT, respectively, and automatically fused by the software. Image data were decay corrected to injection time (Albira, Bruker, Ettlingen, Germany) and expressed as \% ID/cc (PMOD, PMOD Technologies). Tumour-to-muscle ratios (T/M) were calculated by dividing the activity present in the tumour by the activity present in the muscle.

\subsection{Statistical Analysis}

Student's $t$-test was used to determine whether there were any statistically significant differences between the means of two independent (unrelated) groups. The threshold for statistical significance was set at $p<0.05$. 


\section{Conclusions}

The new DOTA derivative of curcumin (DOTA-C21) displayed coordinating property typical of DOTA structure, with the involvement of nitrogen atoms of the rings and two carboxylic arms, as demonstrated by NMR and MS analysis. Gallium-68 labelling conditions are harsh $\left(95^{\circ} \mathrm{C}, 5^{\prime}\right)$, however they provide good RCY and RCP in spite of the methods used for the reaction (prepurification of the eluate or direct labelling and postpurification). Despite high instability of curcumin in physiological conditions, stability of ${ }^{68} \mathrm{Ga}$-DOTA-C21 in mouse blood appears comparable, if not superior, to previously reported ${ }^{18} \mathrm{~F}$-labelled curcumin derivatives, and these data are compatible with diagnostic applications. ${ }^{68}$ Ga-DOTA-C21 rapidly accumulated in colorectal xenograft tumours but after $1.5 \mathrm{~h}$ post injection, exhibits a slow absorption rate into the main organs and a high amount of activity in blood. Unfortunately, the high uptake in blood, liver and intestines prevents the direct use of this derivatives as an imaging agent for colorectal cancer. However, further studies are needed to understand the mechanism of accumulation of ${ }^{68} \mathrm{Ga}$-DOTA-C21 and to design strategies to increase its selectivity for colorectal tumour since the molecular structure of this radiotracer is an interesting foundation to develop further compounds with improved stability and pharmacokinetics.

Supplementary Materials: The following supplementary materials are available online http:/ /www.mdpi.com/ 1420-3049/24/3/644/s1: Chemical characterization of ligand and complexes, Quality controls on radioactive preparations, Figure S1: ESI-LC-MS analysis of DOTA-C21,Figure S2: ${ }^{1} \mathrm{H}-\mathrm{NMR}$ spectra of DOTA-C21 in $\mathrm{D}_{2} \mathrm{O}$ and in MeOD- $d_{4}$ at $25{ }^{\circ} \mathrm{C}$, Figure S3: ${ }^{13} \mathrm{C}-\mathrm{NMR}$ spectra of DOTA-C21 in MeOD- $d_{4}$ at $25{ }^{\circ} \mathrm{C}$, Figure S4: ESI-LC/MS analysis of Ga-DOTA-C21, Figure S5: Detailed ESI-LC/MS of one Ga-DOTA-C21 isomer, Figure S6: ${ }^{1} \mathrm{H}-\mathrm{NMR}$ titration of DOTA-C21 with $\mathrm{Ga}^{3+}$, Figure S7: Aliphatic region of ${ }^{1} \mathrm{H}-,{ }^{1} \mathrm{H}-\mathrm{COSY}-\mathrm{NMR}$ spectrum of Ga-DOTA-C21 in MeOD- $d_{4}$ at $25^{\circ} \mathrm{C}$ ([DOTA-C21] $=0.63 \mathrm{mM}$ ), Figure S8: LC/MS fragmentation experiments on curcumin, Figure S9: UV-vis absorption spectra of the system $\mathrm{Ga}^{3+}$ /DOTA-C21, Figure S10: Fluorescence emission spectra of the system $\mathrm{Ga}^{3}+$ /DOTA-C21,Figure S11: TLC analyses of ${ }^{68} \mathrm{Ga}$-DOTA-C21 prepared by using the post processing method, Figure S12: Average biodistribution of ${ }^{68} \mathrm{Ga}$-DOTA-C21 extracted from micro-PET data at various time points post i.p. and i.v. injection. Correlation between T/M ratio and tumour size, Figure S13: In vivo stability of ${ }^{68}$ Ga-DOTA-C21 in murine blood samples.

Author Contributions: Conceptualization, E.F. and M.A.; Data curation, G.O.; Funding acquisition, E.F., M.A., D.P.-W.; Investigation, G.B., F.P., and G.O.; Methodology, S.R., G.O., M.I., P.C.C., G.B. T.W.L.; Supervision, E.F. and M.A.; Writing-review and editing, E.F., F.P. and M.A.

Funding: This work was supported in part by FAR 2015 grant to E.F. by the University of Modena and Reggio Emilia and NIH P30CA016672.

Acknowledgments: The authors want to thank the University of Modena and Reggio Emilia for financial support (FONDO DI ATENEO PER LA RICERCA ANNO 2015-FAR2015). The authors thank Jean-Philippe Sinnes for the laboratory assistance and Chiara Coruzzi for the bibliographic research as well. The Small Animal Imaging Facility at UT MD Anderson Cancer Center is also acknowledged for assistance with injections and imaging and was supported by NIH P30CA016672.

Conflicts of Interest: The authors declare no conflict of interest.

\section{Abbreviations}

$\begin{array}{ll}\text { PBS } & \text { phosphate buffer saline } \\ \text { i.p. } & \text { intra-peritoneal injection } \\ \text { i.v. } & \text { intra-venous injection } \\ \text { DOTA-NHS } & \text { tetraazacyclododecane-1,4,7,10-tetraacetic acid mono-N-hydroxysuccinimide ester } \\ \text { ESI-LC/MS } & \text { liquid chromatography/mass spectrometry electrospray ionisation } \\ \mathrm{NH}_{4} \mathrm{Ac} & \text { ammonium acetate } \\ \mathrm{NMR} & \text { nuclear magnetic resonance } \\ \mathrm{HBED}-\mathrm{CC}: & \mathrm{N}, \mathrm{N}^{\prime} \text {-Bis(2-hydroxy-5-(ethylene-beta-carboxy)benzyl)ethylenediamine } N, N^{\prime} \text {-diacetic acid } \\ \text { THP } & \text { tris(hydroxypyridinone) } \\ \text { TLC } & \text { thin layer chromatography; SPE: solid phase extraction }\end{array}$




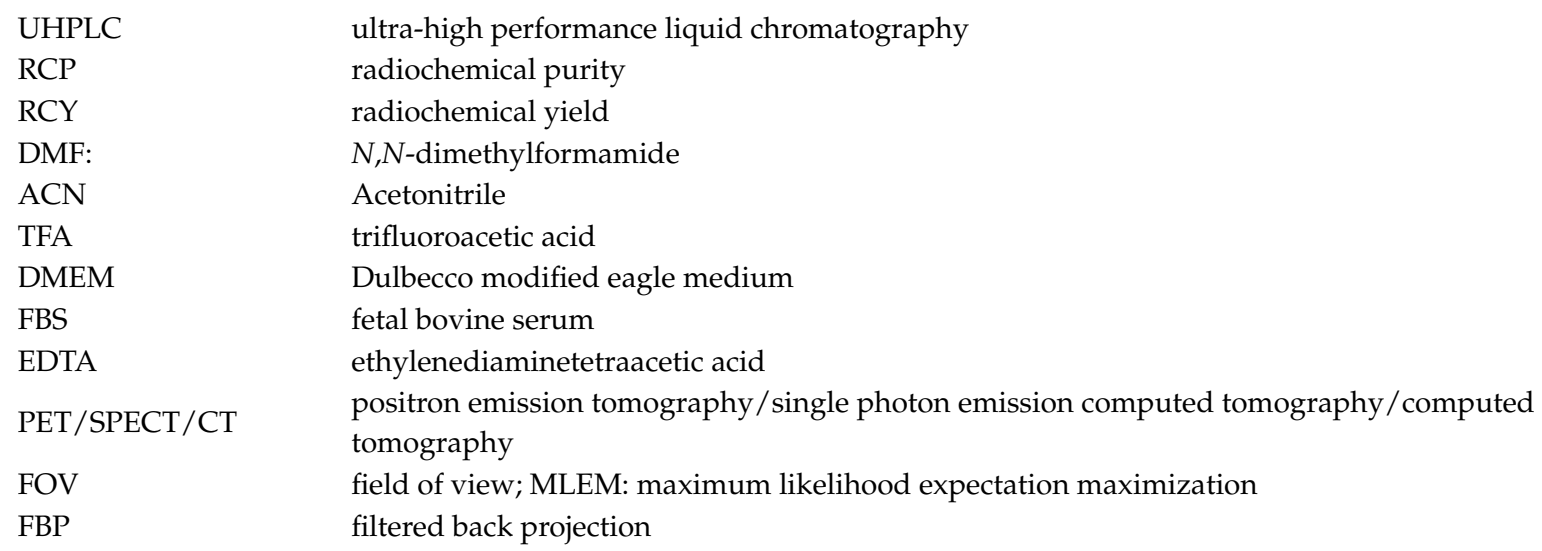

\section{References}

1. Ferlay, J.; Bray, F.; Pisani, P.; Parkin, D.M. GLOBOCAN 2002: Cancer Incidence, Mortality and Prevalence Worldwide; International Agency for Research on Cancer: Lyon, France, 2004.

2. Boyle, P.; Langman, J.S. ABC of colorectal cancer: Epidemiology. BMJ 2000, 321, 805-808. [CrossRef] [PubMed]

3. Pavan, A.R.; Silva, G.D.; Jornada, D.H.; Chiba, D.E.; Fernandes, G.F.; Man Chin, C.; Dos Santos, J.L. Unrevealing the Anticancer Effect of Curcumin and Resveratrol. Nutrients 2016, 8, 628. [CrossRef] [PubMed]

4. Aggarwal, B.B.; Kumar, A.; Bharti, A.C. Anticancer potential of curcumin: Preclinical and clinical studies. Anticancer Res. 2003, 23, 363-398. [PubMed]

5. Sharma, R.A.; Gescher, A.J.; Steward, W.P. Curcumin: The story so far. Eur. J. Cancer 2005, 41, $1955-1968$. [CrossRef] [PubMed]

6. Singh, S.; Khar, A. Biological effects of curcumin and its role in cancer chemoprevention and therapy. Anticancer Agents Med. Chem. 2006, 6, 933-946.

7. Shishodia, S.; Sethi, G.; Aggarwal, B.B. Curcumin: Getting back to the roots. Ann. N. Y. Acad. Sci. 2005, 1056, 206-217. [CrossRef] [PubMed]

8. Van Erk, M.J.; Teuling, E.; Staal, Y.C.; Huybers, S.; Van Bladeren, P.J.; Aarts, J.M.; Van Ommen, B. Time- and dose-dependent effects of curcumin on gene expression in human colon cancer cells. J. Carcinog. 2004, 3. [CrossRef] [PubMed]

9. Mukhopadhyay, A.; Banerjee, S.; Stafford, L.J.; Xia, C.; Liu, M.; Aggarwal, B.B. Curcumin-induced suppression of cell proliferation correlates with down-regulation of cyclin D1 expression and CDK4-mediated retinoblastoma protein phosphorylation. Oncogene 2002, 21, 8852-8861. [CrossRef] [PubMed]

10. Basile, V.; Ferrari, E.; Lazzari, S.; Belluti, S.; Pignedoli, F.; Imbriano, C. Curcumin derivatives: Molecular basis of their anti-cancer activity. Biochem. Pharmacol. 2009, 78, 1305-1315. [CrossRef] [PubMed]

11. Sa, G.; Das, T. Anti cancer effects of curcumin: Cycle of life and death. Cell Div. 2008, 3, 14-28. [CrossRef] [PubMed]

12. Ryu, E.K.; Choe, Y.S.; Lee, K.H.; Choi, Y.; Kim, B.T. Curcumin and dehydrozingerone derivatives: Synthesis, radiolabeling, and evaluation for beta-amyloid plaque imaging. J. Med. Chem. 2006, 49, 6111-6119. [CrossRef] [PubMed]

13. Rokka, J.; Snellman, A.; Zona, C.; La Ferla, B.; Nicotra, F.; Salmona, M.; Forloni, G.; Haaparanta-Solin, M.; Rinne, J.O.; Solin, O. Synthesis and evaluation of a (18)F-curcumin derivate for $\beta$-amyloid plaque imaging. Bioorg. Med. Chem. 2014, 22, 2753-2762. [CrossRef] [PubMed]

14. Asti, M.; Ferrari, E.; Croci, S.; Atti, G.; Rubagotti, S.; Iori, M.; Capponi, P.C.; Zerbini, A.; Saladini, M.; Versari, A. Synthesis and characterization of (68)Ga-labeled curcumin and curcuminoid complexes as potential radiotracers for imaging of cancer and Alzheimer's disease. Inorg. Chem. 2014, 53, 4922-4933. [CrossRef] [PubMed]

15. Rubagotti, S.; Croci, S.; Ferrari, E.; Orteca, G.; Iori, M.; Capponi, P.C.; Versari, A.; Asti, M. Uptake of Ga-curcumin derivatives in different cancer cell lines: Toward the development of new potential 68Ga-labelled curcuminoids-based radiotracers for tumour imaging. J. Inorg. Biochem. 2017, 173, 113-119. [CrossRef] [PubMed] 
16. Nelson, K.M.; Dahlin, J.L.; Bisson, J.; Graham, J.; Pauli, G.F.; Walters, M.A. The Essential Medicinal Chemistry of Curcumin. J. Med. Chem. 2017, 60, 1620-1637. [CrossRef]

17. Benassi, R.; Ferrari, E.; Grandi, R.; Lazzari, S.; Saladini, M. Synthesis and characterization of new $\beta$-diketo derivatives with iron chelating ability. J. Inorg. Biochem. 2007, 101, 203-213. [CrossRef]

18. Nardo, L.; Maspero, A.; Selva, M.; Bondani, M.; Palmisano, G.; Ferrari, E.; Saladini, M. Excited-State Dynamics of Bis-dehydroxycurcumin Carboxylic Acid, a Water-Soluble Derivative of the Photosensitizer Curcumin. J. Phys. Chem. 2012, 116, 9321-9330. [CrossRef]

19. Zhernosekov, K.P.; Filosofov, D.V.; Baum, R.P.; Aschoff, P.; Bihl, H.; Razbash, A.A.; Jahn, M.; Jennewein, M.; Rösch, F. Processing of Generator-Produced 68Ga for Medical Application. J. Nucl. Med. 2007, 48, 1741-1748. [CrossRef]

20. Upton, R.N. The two-compartment recirculate pharmacokinetic model-an introduction to recirculatory pharmacokinetic concepts. Brit. J. Anaesthesia 2004, 92, 475-484. [CrossRef]

21. Morris, E.D.; Endres, C.J.; Schmidt, K.C.; Christian, B.T.; Muzic, R.F.; Fisher, R.E. Kinetic modelling in positron emission tomography. In Emission Tomography; Elsevier: San Diego, CA, USA, 2004; Chapter 23; pp. 499-540.

22. Ravindran, J.; Prasad, S.; Aggarwal, B.B. Curcumin and Cancer Cells: How Many Ways Can Curry Kill Tumor Cells Selectively? AAPS J. 2009, 11, 495-510. [CrossRef]

23. Tang, M.; Taghibiglou, C. The Mechanisms of Action of Curcumin in Alzheimer's Disease. J. Alzheimers Dis. 2017, 58, 1003-1016. [CrossRef] [PubMed]

24. He, Y.; Yue, Y.; Zheng, X.; Zhang, K.; Chen, S.; Du, Z. Curcumin, inflammation, and chronic diseases: How are they linked? Molecules 2015, 20, 9183-9213. [CrossRef] [PubMed]

25. Cunningham, D.; Atkin, W.; Lenz, H.J.; Lynch, H.T.; Minsky, B.; Nordlinger, B.; Starling, N. Colorectal Cancer. Lancet 2010, 375, 1030-1047. [CrossRef]

26. Seemann, J.; Eppard, E.; Waldron, B.P.; Ross, T.L.; Roesch, F. Cation exchange-based postprocessing of 68Ga-eluate: A comparison of three solvent systems for labelling of DOTATOC, NO2AP(BP) and DATA (m.). Appl. Radiat. Isot. 2015, 98, 54-59. [CrossRef] [PubMed]

27. Tsionou, M.I.; Knapp, C.E.; Foley, C.A.; Munteanu, C.R.; Cakebread, A.; Imberti, C.; Eykyn, T.R.; Young, J.D.; Paterson, B.M.; Blower, P.J. Comparison of macrocyclic and acyclic chelators for gallium-68 radiolabelling. RSC Adv. 2017, 7, 49586-49599. [CrossRef]

28. Mizwicki, M.T.; Menegaz, D.; Yaghmaei, S.; Henry, H.L.; Norman, A.W. A molecular description of ligand binding to the two overlapping binding pockets of the nuclear vitamin D receptor (VDR): Structure-function implications. J. Steroid. Biochem. 2010, 121, 98-105. [CrossRef] [PubMed]

29. Bartik, L.; Whitfield, G.K.; Kaczmarska, M.; Lowmiller, C.L.; Moffet, E.W.; Furmick, J.K.; Hernandez, Z.; Haussler, C.A.; Haussler, M.R.; Jurutka, P.W. Curcumin: A novel nutritionally derived ligand of the vitamin D receptor with implications for colon cancer chemoprevention. J. Nutr. Biochem. 2010, 21, 1153-1161. [CrossRef] [PubMed]

30. Mohammadi, F.; Bordbar, A.K.; Divsalar, A.; Mohammadi, K.; Saboury, A.A. Analysis of binding interaction of curcumin and diacetylcurcumin with human and bovine serum albumin using fluorescence and circular dichroism spectroscopy. Protein J. 2009, 28, 189-196. [CrossRef]

31. Sato, H.; Chuang, V.T.; Yamasaki, K.; Yamaotsu, N.; Watanabe, H.; Nagumo, K.; Anraku, M.; Kadowaki, D.; Ishima, Y.; Hirono, S.; et al. Differential effects of methoxy group on the interaction of curcuminoids with two major ligand binding sites of human serum albumin. PLoS ONE 2014, 9, e87919. [CrossRef]

32. Cui, M.; Ono, M.; Kimura, H.; Liu, B.; Saji, H. Synthesis and Structure_Affinity Relationships of Novel Dibenzylideneacetone Derivatives as Probes for $\beta$-Amyloid Plaques. J. Med. Chem. 2011, 54, 2225-2240. [CrossRef]

Sample Availability: Samples of the compounds are not available from the authors. 